University of Louisville

ThinkIR: The University of Louisville's Institutional Repository

Electronic Theses and Dissertations

$5-2017$

\title{
Expression of ZEB factors in oral squamous cell carcinoma.
}

\author{
Saira Ahmed \\ University of Louisville
}

Follow this and additional works at: https://ir.library.louisville.edu/etd

Part of the Oral Biology and Oral Pathology Commons

\section{Recommended Citation}

Ahmed, Saira, "Expression of ZEB factors in oral squamous cell carcinoma." (2017). Electronic Theses and Dissertations. Paper 2726.

https://doi.org/10.18297/etd/2726

This Master's Thesis is brought to you for free and open access by ThinkIR: The University of Louisville's Institutional Repository. It has been accepted for inclusion in Electronic Theses and Dissertations by an authorized administrator of ThinkIR: The University of Louisville's Institutional Repository. This title appears here courtesy of the author, who has retained all other copyrights. For more information, please contact thinkir@louisville.edu. 
EXPRESSION OF ZEB FACTORS IN ORAL SQUAMOUS CELL CARCINOMA

\author{
By \\ Saira Ahmed \\ B.A. University of Miami, 2006 \\ A Thesis \\ Submitted to the Faculty of \\ The School of Dentistry of the University of Louisville \\ For the degree of \\ Master of Science \\ In Oral Biology \\ Department of Oral Immunology and Infectious Diseases \\ University of Louisville \\ Louisville, KY
}

May 2017 



\title{
EXPRESSION OF ZEB FACTORS IN ORAL SQUAMOUS CELL CARCINOMA
}

\author{
By \\ Saira Ahmed \\ B.A. University of Miami, 2006
}

A Thesis Approved on

March 26, 2017

by the following Thesis Committee

Douglas S. Darling, $\mathrm{PhD}$, Mentor

David A. Scott, PhD, Committee Member

Brian S. Shumway, DDS, MS, Committee Member 


\section{DEDICATION}

I dedicate this thesis to my mother, Farhana Ahmed, and my sister, Zahra Ahmad. 


\section{ACKNOWLEDGEMENTS}

I would sincerely like to acknowledge my research mentor Dr. Douglas Darling for allowing me to work in his lab for my research. I would not have been able to successfully complete my project without his guidance and patience. 


\section{ABSTRACT \\ ZEB FACTORS IN ORAL SQUAMOUS CELL CARCINOMA \\ Saira Ahmed}

March 26, 2017

Objectives: The ZEB family of transcription factors (ZEB1 and ZEB2) have been demonstrated to play a role in metastatic progression of several cancers, and may also influence the initial transformation and generation of cancer stem cells. However, the expression pattern of ZEB proteins in the development of oral squamous cell carcinoma has not been investigated. The purpose of this study was to define changes in expression and subcellular localization of the ZEB family in both precancerous lesions and different grades of OSCC.

Materials and Methods: Seventy-nine tongue biopsies were subjected to immunohistochemistry and immunofluorescence to determine the expression and subcellular location of ZEB1 and ZEB2 across six histological grades of precancerous and cancerous lesions.

Results: Surprisingly, Both ZEB1 and ZEB2 exhibit changes in subcellular location between healthy tissue, dysplasia, carcinoma in situ, and well differentiated, moderately differentiated, and poorly differentiated carcinoma. ZEB1 expression in healthy tissue is mainly nuclear. As carcinoma progresses, subsets of patients show either primarily cytosolic or primarily nuclear ZEB1 in tumors. In histologically normal tissue, ZEB2 is expressed in the cytosol of a band of suprabasal cells. In early grades of carcinoma it 
remains cytosolic, but in more advanced carcinoma becomes a mix of cells with either nuclear or cytosolic ZEB2.

Conclusions: Changes of subcellular distribution of ZEB1 and ZEB2 occur during development of oral squamous cell carcinoma. Cytosolic localization of either ZEB1 or ZEB2 likely disrupts their ability to regulate transcription. The presence of patients with differences in ZEB1 or ZEB2 localization suggest that there may be different clinical outcomes related to different patterns of expression. 
TABLE OF CONTENTS

PAGE

DEDICATIONS ..........................................................iv

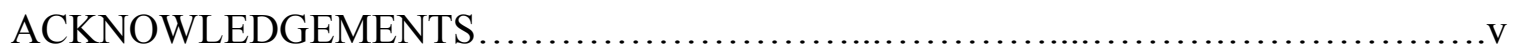

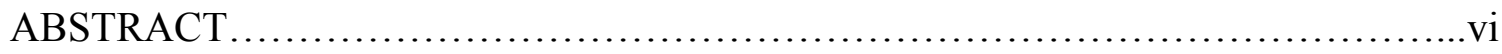

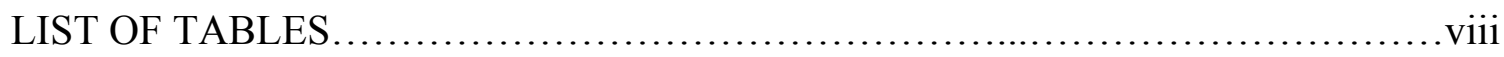

LIST OF FIGURES.......................................................

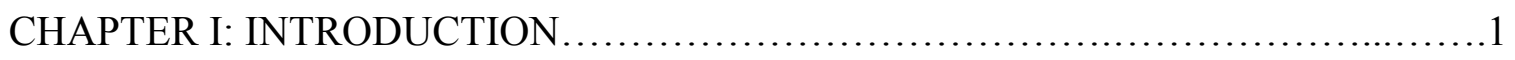

CHAPTER II: MATERIALS AND METHODS ................................... 18

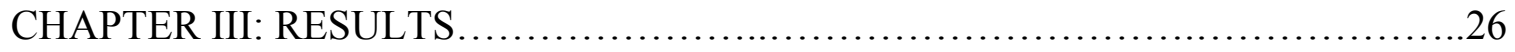

CHAPATER IV: DISCUSSION ...............................................

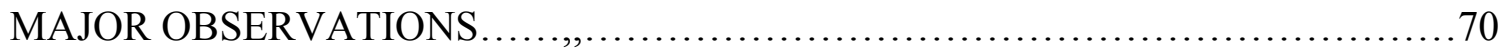

FUTURE DIRECTIONS................................................ 71

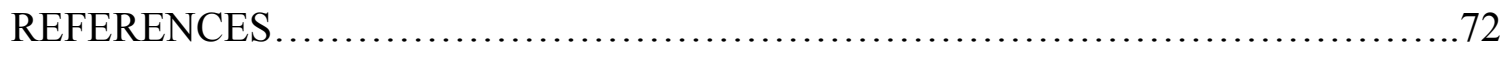

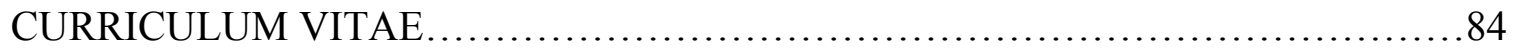




\section{LIST OF TABLES}

PAGE

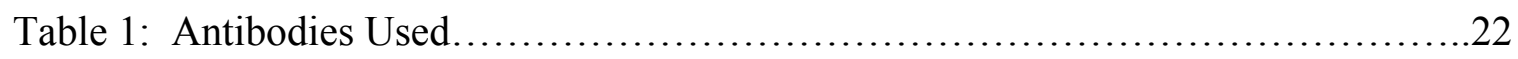

Table 2: ZEB2 Expression Summary in Fibroma..................................28

Table 3: ZEB2 Expression Summary in Mild Dysplasia................................

Table 4: ZEB2 Expression Summary Moderate Dysplasia..........................34

Table 5: ZEB2 Expression Summary Severe Dysplasia........................... 37

Table 6: ZEB2 Expression Summary Carcinoma In Situ.........................40

Table 7: ZEB2 Expression Summary Well Differentiated Carcinoma.................43

Table 8: ZEB2 Expression Summary Moderately Differentiated Carcinoma...........46

Table 9: ZEB2 Expression Summary Poorly Differentiated Carcinoma................49

Table 10: Summary of ZEB2 Statistics.....................................52

Table 11: ZEB1 Expression Summary........................................56 


\section{LIST OF FIGURES}

PAGE

Figure 1: ZEB1 and ZEB2 Domain Structures............................... 12

Figure 2: Epithelial Tissue Structures........................................ 24

Figure 3: ZEB2 Expression in Fibroma........................................29

Figure 4: ZEB2 Expression in Mild Dysplasia................................ 32

Figure 5: ZEB2 Expression in Moderate Dysplasia............................. 35

Figure 6: ZEB2 Expression in Severe Dysplasia.................................. 38

Figure 7: ZEB2 Expression in Carcinoma in Situ...............................41

Figure 8: ZEB2 Expression in Well Differentiated Carcinoma......................44

Figure 9: ZEB2 Expression in Moderately Differentiated Carcinoma..................47

Figure 10: ZEB2 Expression Poorly Differentiated Carcinoma.......................50

Figure 11: Graph of ZEB2 Data............................................

Figure 12: ZEB1 Expression in Oral Epithelia Dysplasia, Carcinoma in Situ, and Squamous Cell Carcinoma.................................................... 57

Figure 12: ZEB1 and ZEB2 Comparison......................................58 


\section{CHAPTER I}

\section{INTRODUCTION}

\section{OSCC Background}

Worldwide, oral squamous cell carcinoma (OSCC) remains one of the most prevalent cancers, with the yearly incidence being about 400,000 new cases diagnosed with over 200,000 deaths (Chaturvedi, Anderson et al. 2013). The five year survival for OSCC is approximately 50\%; importantly, this has remained the same for the past several decades (Warnakulasuriya 2009). Furthermore, the treatment options for OSCC oftentimes result in reduced quality of life due to invasive surgical techniques. OSCC is a subset of head and neck squamous cell carcinoma; it includes squamous cell carcinomas of the lip, tongue, and the oral cavity (Warnakulasuriya 2009). Early stages of oral cancer may be cured by either surgery or radiation (Tsantoulis, Kastrinakis et al. 2007). More advanced cancers require surgery followed by subsequent radiation. In the United States, OSCC is predominantly related to tobacco use (Vigneswaran and Williams 2014). Other risk factors include excessive alcohol consumption, bethel quid use, and the human papilloma virus (Warnakulasuriya 2009). The best way to prevent OSCC is smoking cessation and reduction in alcohol consumption. 
One other major risk factor that is associated with OSCC is the human papilloma virus (Tsantoulis, Kastrinakis et al. 2007). Specifically, the HPV virus can interfere with the tumor suppressor $\mathrm{p} 53$ and subsequently blocks the downstream activity of $\mathrm{pRb}$ resulting in the interference with DNA replication and decreased normal apoptotic activity (Andrews, Seaman et al. 2009). Impairment of the cell's mechanisms to protect against aberrant growth allows tumor proliferation. (Remove?)

OSCC is the sixth most common cancer worldwide, and commonly occurs in many Asian countries. Generally, the incidence in men is two times as great as in women. These numbers have been consistent in men between the years 2006-2010. The incidence in women has decreased $0.9 \%$ annually from 2006-2010. Oral squamous cell carcinoma associated with human papilloma virus has been increasing among white men and women. The number of deaths expected from carcinoma of the oral cavity and pharynx in 2014 is 8,390 . Over the past three decades, death rates have been falling (American Cancer Society.). The mortality rate is about 50\% and has remained at this level for the past three decades. One of the main reasons for this lies in the fact that OSCC is often difficult to diagnose until the caner has metastasized to distant organ sites. To date, there have not been any established protocols or diagnostic tools for the early detection of OSCC (Lingen, Kalmar et al.). Currently, the standard of care is routine oral cancer screenings in at-risk populations, particularly in high-risk areas such as the floor of the mouth, the retromolar pad area, the tonsillar pillars, and the latero-ventral tongue.

Another area of concern regarding OSCC is the fact that in many cases the carcinomas are initially responsive to treatments such as radiotherapy and chemotherapy, but relapse is common (Chen, Zimmermann et al. 2013). Treatment relapse occurs both 
at local and distant sites. Thus, poor prognosis results from both metastatic disease and the recurrence of OSCC. Often, recurrent disease is either inoperable or resistant to conventional therapy such as chemotherapy or radiation. Mortality due to OSCC is frequently caused by cervical lymph node metastasis (Chu, Hu et al. 2013).

\section{Development of OSCC}

Carcinogenesis of the oral epithelium proceeds through a spectrum of precursor lesions that may progress to OSCC; including oral epithelial dysplasia (OED) and carcinoma in situ (CIS). Clinically, OED most often presents as white, red or a mixture of white and red lesions (Brennan, Migliorati et al. 2007). The white lesions are referred to as leukoplakia, the red ones as erythroplakia and the mixture as speckled leukoplakia. These lesions are characterized as surface lesions on the oral mucosa. Within OED there are three different grades: mild, moderate, and severe. Each of these grades is based upon the extent of histological deviation from normal epithelial tissue architecture and maturation. Mild dysplasia shows aberrations to the lower one-third of the epithelium, moderate involves one-half, and severe through two-thirds of the epithelial thickness (Woolgar and Triantafyllou 2011). When dysplastic changes become more pronounced and involve the whole thickness of the epithelium, the lesion is considered to be carcinoma in situ (CIS) (Kumar, Abbas et al. 2013). CIS is not considered to be cancer; the distinction being that has not yet invaded the surrounding connective tissue.

Once CIS has invaded the adjacent connective tissue it may be classified as welldifferentiated, moderately differentiated or poorly differentiated carcinoma. Well- 
differentiated carcinoma is characterized by the presence of keratin pearls which indicate a high degree of differentiation (Woolgar and Triantafyllou 2011). Moderately differentiated carcinoma is characterized by the presence of abnormal keratinization. Poorly differentiated carcinoma is identified by highly irregular tissue architecture.

All cancers possess certain characteristics and oral carcinomas are not an exception. These hallmarks include: evading apoptosis, self-sufficiency in growth signals, insensitivity to anti-growth signals, sustained angiogenesis, limitless replicative potential, and tissue invasion and metastasis (Hanahan and Weinberg 2000). Invasion and metastasis are of growing concern in regards to OSCC because the majority of OSCC related deaths are related to primary tumors metastasizing to distant tissue sites, including lymph nodes and other organs (Chu, Hu et al. 2013).

Tumor cells become invasive by specific molecular mechanisms. One such mechanism that has been implicated in tumor invasion is the epithelial to mesenchymal transition (EMT) (Chu, Hu et al. 2013). This process allows cells to increase their invasiveness by undergoing changes in morphology, loss of polarity, and loss of cell to cell contacts (Chen, Zimmermann et al. 2013). EMT is not exclusively a tumorigenic process - it is present during embryonic development and homeostatic processes such as wound healing. EMT in cancer progression is induced by the TGF- $\beta$ pathway via Smad signaling (Lamouille, Xu et al. 2014).

Epithelial to mesenchymal transition (EMT)

Epithelial tissue can be either one layer of or multiple layers (Lamouille, Xu et al. 2014). Cells of the epithelium communicate through intracellular junctions. Since the 
epithelium is highly specialized, it was previously thought that epithelial cells are inalterably programmed to retain their phenotype, but this is not the case (Kalluri and Neilson 2003). Epithelial cells retain some degree of plasticity and are able to change their phenotype. The process of epithelial cells undergoing changes to express a mesenchymal phenotype is termed epithelial-to-mesenchymal transition (EMT). EMT is a mechanism used for forming fibroblasts in injured tissues and spreading cells in vertebrate embryos. Furthermore, mature epithelium can undergo EMT in certain situations such as inflammation or wounding-healing that can lead to the production of fibroblasts and fibrogenesis (Vered, Dayan et al. 2010).

The process of EMT leads to the disruption of the basement membrane; this process is aided by matrix metalloproteases or membrane assembly inhibitors (Kalluri and Neilson 2003). Disruption of cell adhesion is observed in many cancers, it correlates with poor prognosis and metastasis (Comijn, Berx et al.). Epithelial-cadherin (Ecadherin), is an integral component of the epithelial junctional system. It maintains cellcell adhesion, having an extracellular domain which binds adjacent cells, and links intracellularly through catenin to the actin cytoskeleton. E-cadherin suppresses invasion by tumor cells. Conversely, loss of E-cadherin results in increased invasion.

EMT has been implicated in development, wound-healing, fibrosis, and cancer progression (Bronsert, Kohler et al. 2014). It's involvement with cancer is specifically with the process of metastasis. EMT in cancer can lead to increased invasion and motility. EMT of carcinoma cells has been linked to the acquisition of cancer stem cell traits such as resistance to chemotherapy and increased tumorgenicity, the reason for this being that once epithelial cells become more mesenchymal they also resist senescence 
and apoptosis (Lamouille, Xu et al. 2014). There are several transcription factors that have been implicated in driving EMT, including ZEB1, ZEB2, TWIST, and Slug (Chen, Zimmermann et al. 2013). Since metastasis is a leading cause of mortality for patients with OSCC, the process and those transcription factors that govern it should be further analyzed. EMT is a process that is temporary, whereby epithelial cells transiently become mesenchymal and can revert to the epithelial phenotype once they have populated other tissues (Lamouille, Xu et al. 2014).

After epithelial cells undergo malignant transformation, they become more amorphous and the tissue itself becomes less organized. While cells are undergoing these changes, cells also become detached from each other and therefore are not well-anchored. Claudin and other occluding proteins are down-regulated in order for tight junctions to be dissolved. EMT drives the process of metastasis by allowing tumor cells to migrate away from the initial tumor location and circulate as circulating tumor cells (CTCs).

One of the ways in which EMT is induced by the TGF- $\beta$ pathway is via Smad signaling. TGF- $\beta$ is a family of cytokines that play roles in processes such as fibrosis and wound healing (Kalluri and Neilson 2003) (Chu, Hu et al. 2013). It has been shown in cell culture studies that cells will adopt mesenchymal characteristics in the presence of the TGF- $\beta$, during this process, the transcription factors ZEB1, ZEB2, Snail, and Slug may also be upregulated (Gregory, Bracken et al. 2011). EMT may also be induced via the Wnt/beta-catenin pathway; the disruption of this pathway has been demonstrated to influence tissue differentiation (Shiah, Shieh et al. 2016).

In addition to changes in cell adhesion, the actual morphology of the cells changes during EMT (Lamouille, Xu et al. 2014). The cytoskeleton undergoes changes that 
enable the cell to become elongated. The cell forms projections that allow it to promote movement. The new membrane projections are actin-rich thereby conferring proteolytic function in the newly formed invadipodia. Also during EMT, cells become more contractile due to the actin stress fiber formation.

In EMT not only is E-cadherin down-regulated, there is a phenomenon known as a "cadherin-switch." (Lamouille, Xu et al. 2014) In this process, E-cadherin is downregulated, the consequence of this being that the cells are allowed to become more invasive. E-cadherin allows cells to be anchored in place. Another change in gene expression also occurs in the cytoskeletal elements. Cytokeratins are repressed while the expression of vimentin is enhanced. Also during EMT, the extracellular matrix is being remodeled which then alters cell interactions.

It has been shown experimentally that when ZEB2 binds at the two highly conserved E2 boxes within the E-cadherin promoter it represses the activity of the gene (Comijn, Berx et al.). In this particular experiment, ZEB2 was co-transfected with reporter plasmids driven by the E-cadherin promoter in the E-cadherin positive cell line MDCK. ZEB2 caused an $80 \%$ decrease in the activity of the E-cadherin promoter. Mutation of either zinc finger domain resulted in less repression. Furthermore, it was shown that in E-cadherin positive cells, E-cadherin expression can be repressed by exogenous ZEB2. This repression of E-cadherin by ZEB2 is Snail independent. Interestingly, ZEB2 decreases cell adhesion, but does not increase cell migration. The results for this particular study indicate that ZEB2 can directly repress E-cadherin.

There have been some studies that show that the anti-diabetic drug Metformin can decrease the expression of EMT-inducing factors such as Slug, ZEB1, ZEB2, and Twist 
(Chen, Zimmermann et al. 2013). Theoretically, blocking transcription factors that induce EMT should be a favorable therapy, but before that may be done their exact roles should be understood.

EMT is heavily influenced by both ZEB1 and ZEB2, but it is also regulated by microRNAs. MicroRNAs (miRs) are small, non-coding single strands of RNA that can block protein synthesis by inhibiting mRNA translation or promoting its degradation; miRs can act by targeting the 3' untranslated region (Sun, Zhang et al. 2014). Mounting evidence shows that miRs can play a role in different processes such as cellular growth, differentiation, and development. In melanoma and lung adenocarcinoma it has been shown that the miR-200 family inhibits EMT by repressing ZEB1 and ZEB2 expression (Chu, Hu et al. 2013). In cell culture studies, it has been demonstrated that the miR-200 family and miR-205 are downregulated in those cells that had undergone EMT (Gregory, Bert et al. 2008). Conversely, those cells that were expressing microRNAs showed downregulation of EMT markers. The way the miR-200 family inhibits EMT-activators is by inducing epithelial differentiation; they promote the epithelial phenotype (Wellner, Schubert et al. 2009). It has been demonstrated that there is a double-feedback loop governing the expression of EMT factors and certain families of microRNAs. For example, the ZEB family transcriptionally represses miR-200, but also miR-200 acts as a post-transcriptional repressor of ZEB factors (Brabletz and Brabletz 2010). This, however, is not acting alone. There is also interplay with another pair, the miR-34/Snail, loop that is also influencing gene expression (Lu, Jolly et al. 2013). Along with ZEB factors, Snail also represses the miR-200 as well as miR-34. Both ZEB1 and ZEB2 are influencing the expression of both micro-RNAs, but both microRNAs are not influencing 
both. In other words, only miR-34 is affecting Snail while only miR-200 is affecting ZEB.

Overall, there are many potential therapeutic targets with regards to EMT, however, different cancers are driven by different players such as ZEBs, Snails, Wnts, TGFs, micro RNAs, etc. An improved understanding of EMT in OSCC is needed in order to effectively block EMT (Chen, Zimmermann et al. 2013).

\section{ZEB Family of Transcription Factors}

The ZEB family of transcription factors have been implicated in various biological processes in development, wound healing and cancer progression. Specifically, the ZEB family of proteins plays a role in tumor invasiveness and metastasis as well as increased resistance to chemotherapy (Sanchez-Tillo, Siles et al. 2011).

The superfamily of zinc finger and homeodomain transcription factors is represented in all animals. In Drosophila, Zfh-1 represents the mammalian ZEB superfamily, and Drosophila Zfh2 represents ATBF1, Zfh4, ZFh5, subfamily (Miyoshi, Maruhashi et al. 2006). In humans, the ZEB family contains two members, ZEB1 and ZEB2. Both of these proteins are also known by other names. ZEB1 for instance is also referred to as $\delta E F 1, A R E B 6, B Z P$, MEB1, Nil-2-a, TCF8, ZEB, ZEB-1, Zfhep1, and Zfhx1a. ZEB2 is also referred to as KIA0569, SIP1, SMAIDIP-1, ZEB-2, and Zfhx1b (Peinado, Olmeda et al. 2007). Both ZEB1 and ZEB2 contain two clusters of zinc fingers that are located at the $\mathrm{N}$-terminus and $\mathrm{C}$-terminus; between these zinc fingers is a homeodomain (Gheldof, Hulpiau et al. 2012). ZEB1 and ZEB2 are highly homologous 
and are required for cell migration during embryonic development. Figure 1 shows the domain structures of ZEB1 and ZEB2. Both ZEB1 and ZEB2 bind to an identical consensus DNA sequence (CACCT) and when they are bound to this consensus sequence, they typically act as transcriptional repressors (Miyoshi, Maruhashi et al. 2006). This binding involves only the zinc fingers, and not the centrally located homeodomain (Furusawa, Moribe et al. 1999). The way in which they can act as transcriptional repressors involves the binding of a co-repressor, C-terminal binding protein (CtBP). CtBPs have been shown to act as transcriptional repressors in conjunction with the ZEB family of transcription factors (Peinado, Olmeda et al. 2007). Human ZEB1 and ZEB2 have very similar amino acid sequences in their ZF domains and homeodomain, but not other areas. In addition to the zinc finger clusters and homeodomain both ZEB proteins have a Smad-interacting domain. ZEB1 and ZEB2 require co-factors in order to be fully active. The presence of the CtBP interacting domain allows them to bind CtBP cofactors. They both target similar gene sequences and act to repress the expression of epithelial genes such as E-cadherin (Bracken, Gregory et al. 2008). In humans, both ZEB1 and ZEB2 are 43\% homologous (Gheldof, Hulpiau et al. 2012). Expression of ZEB1 and ZEB2 have both been implicated in the poor progression of different carcinomas.

ZEB1 specifically can promote cell migration and metastasis through EMT; furthermore ZEB1 endows tumor cells with resistance to radiotherapy independent of EMT (Zhang, Sun et al. 2015). The expression of ZEB1 is controlled by many different signaling pathways including TGF- $\beta$, Wnt, and notch. Additionally, its expression is also regulated by microRNAS. ZEB1 can either be a transcriptional activator or a 
transcriptional repressor. If ZEB1 interacts with the transcriptional co-activators p300/CBP-associated factor, ZEB1 will become a transcriptional activator (Lamouille, Xu et al. 2014) (Nishimura, Manabe et al. 2006). Conversely, interaction with the corepressor CtBP1 leads to inhibition of transcription of the target gene. ZEB1 expression is induced by the TGF- $\beta$ pathway, where it is a critical effector of TGF-beta signaling, as well as the Wnt pathway. ZEB1 expression is also induced by progesterone, loss of which is critical for the onset of parturition since ZEB1 represses the oxytocin gene, hence the fall of progesterone decreasing ZEB1 causes the spike of oxytocin which induces birth (Williams, Renthal et al. 2012). ZEB1 is also induced by growth factors that are responsible for activating the RAS and MAPK pathways. The phosphorylation status of ZEB1 is variable in vivo and therefore may be a target of this pathway (Llorens, Lorenzatti et al. 2016). ZEB1 expression has been observed to be expressed in both cancer and stromal cells (Bronsert, Kohler et al. 2014). In a mouse model, the overexpression of ZEB1 resulted in the suppression of E-cadherin (Liu, El-Naggar et al. 2008). Additionally, ZEB1 also acts as a transcriptional activator of smooth muscle actin and myosin, certain collagens, and vimentin. Vimentin is found to be up-regulated in many different kinds of epithelial carcinomas (Satelli and Li 2011).

ZEB1 is also influenced by p53; it has been shown experimentally that when p53 is knocked out, there is an increase in N-cadherin, ZEB1 and BMI1 as well as reduced levels of miR-200 (Liu, Sanchez-Tillo et al. 2014). 


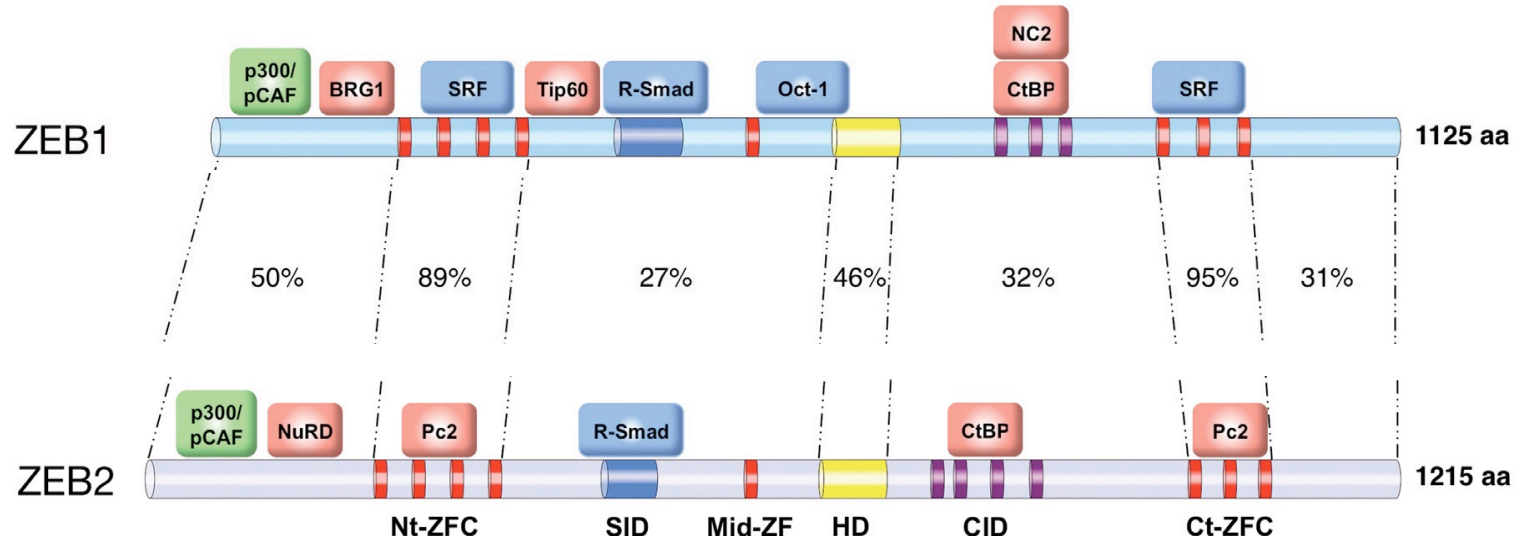

Figure 1: ZEB1 and ZEB2 domain structures. ZEB1 and ZEB2 are similar in the fact that they both contain two zinc-finger binding domains flanking a central homeodomain. Each colored bar on each protein represents a different area; red indicates the zinc finger domain, yellow the homeodomain, the purple represents the CtBP binding site, and blue represents the Smad interacting domain. The percentages indicate the percent homology between the two transcription factors. Interactions with different proteins are shown, based on (Sanchez-Tillo, Siles et al. 2011). 
Developmentally, mutation of ZEB1 leads to secondary palate cleft along with other craniofacial abnormalities (Liu, El-Naggar et al. 2008). During embryonic development it is necessary for single cells to detach and invade, specifically in processes such as neural crest cell migration; both ZEB1 and ZEB2 play a role in this process (Gheldof, Hulpiau et al. 2012). The ZEB1 null mutant mice survive through embryonic development, but apparently die immediately after birth suggesting a defect in the ability to breathe (Takagi, Moribe et al. 1998). ZEB1 knockout mice have also demonstrated abnormal corneal epithelium due to the suppression of the epithelial phenotype (Liu, Peng et al. 2008). In humans, a ZEB1 mutation can cause posterior polymorphous corneal dystrophy because of aberrant corneal endothelium; this mutation is relatively rare and is dominant (Lechner, Dash et al. 2013). ZEB1 is normally expressed in various body tissues including the blood, kidney, eye, and brain and neural crest cells (Kerosuo and Bronner-Fraser 2012) (Higashi, Moribe et al. 1997, Takagi, Moribe et al. 1998). The function of ZEB1 is to act as either a transcriptional activator or repressor. It inhibits the expression of the interleukin-2 gene as well as the expression of E-cadherin (Zhang, Tian et al. 2014). It positively regulates neuronal differentiation. Since it can repress the epithelial phenotype, it can promote tumorigenicity by inhibiting microRNAs.

On the cellular level, ZEB1 may be phosphorylated by kinases. This results in ZEB1 becoming localized to the cytosol (Llorens, Lorenzatti et al. 2016). This phosphorylation is regulated by growth factors such as IGF-1. The larger implication of this phosphorylation is that it transcriptionally inhibits ZEB1 since it is no longer located in the nucleus. 
ZEB2 is also a member of the ZEB family of transcription factors. It is 1214 amino acids long and a $140 \mathrm{kDa}$ protein (Grabitz and Duncan 2012). It is a two-handed zinc finger homeodomain protein. As with ZEB1, the homeodomain is flanked by two zinc finger clusters; containing either four or three fingers (Figure 1) (Comijn, Berx et al.). The homeodomain is located near the center and it mainly participates in proteinprotein interactions [[Smith + Darling 2003]]. In embryonic development ZEB2 is expressed in neural crest cells, neuroepithelium, and limb buds. ZEB2 knockout mice do not survive past 9.5 weeks because the neural tube does not close properly, hence ZEB2 has essential effects in embryogenesis, whereas ZEB1 is only essential after birth. ZEB2 is normally expressed in central nervous tissue, muscle tissue, and hematopoietic cells (Comijn, Berx et al.).

On a subcellular level, ZEB2 interacts with Smads 1,2,3,5, and 8 in its role as an effector of the TGF-beta and bone morphogenetic protein (BMP) pathways. ZEB2 can repress the expression of proteins such as claudins, ZO-3, connexins, E-cadherin, plakophillin 3, desmoplakin, and crumbs3 (Nam, Lee et al. 2012).

ZEB2 aberrations in humans are of consequence. One such example is MowatWilson Syndrome which is the result of a missense mutation in the ZEB2 gene (Ghoumid, Drevillon et al. 2013). Mowat-Wilson syndrome is characterized by mental retardation, microencephaly, short stature, and a distinctive facial appearance. ZEB2 is normally expressed during embryonic development, neurons, and blood and epithelial cells (McKinsey, Lindtner et al. , Korpal, Lee et al. 2008, Tatari, De Craene et al. 2014). Elevated ZEB2 levels have also been observed in several types of cancer including: breast, ovarian, gastrin, and oral squamous cell carcinoma (Rosivatz, Becker et al. 2002) 
By binding to the E-cadherin promoter, ZEB2 represses its transcription (Miyoshi, Maruhashi et al. 2006). In addition to suppressing cell adhesion, ZEB2 has also demonstrated a protective effect on bladder cancer cells from DNA damage induced apoptosis. In human cell lines, it has been demonstrated that when ZEB2 is downregulated then apoptosis is induced by the activation of caspase 3 (Qi, Song et al. 2012). Furthermore, in glioma cells, ZEB2 knockdown resulted in normal E-cadherin expression and decreasing the vimentin expression.

The ZEB family contains two closely related transcription factors, however ZEB1 and ZEB2 are responsible for different functions. For example ZEB1 serves a broad role during development by influencing immune cell differentiation, skeletal patterning and palate formation (Gheldof, Hulpiau et al. 2012). Conversely, ZEB2 plays a role in maintaining the integrity of the epithelial basement membrane (Tatari, De Craene et al. 2014).

\section{Cancer Stem Cells}

OSCC may be especially persistent due to the presence of cancer stem-cells (CSCs) (Chu, Hu et al. 2013). CSCs are an important reason for tumor recurrence, progression, and resistance to radiotherapy. The up-regulation of embryonic stem cell genes such as Oct4 and Nanog, indicate that CSC may possess the ability to be undifferentiated and therefore produce cancer cells via asymmetrical division. When these pathways are up-regulated, tumor cells are more likely to persist since they are slower growing and therefore more resistant to conventional chemotherapeutic agents that target rapidly dividing cells, The roles of ZEB1 and ZEB2 have not yet been understood with respect to the CSC properties of OSCC (Chu, Hu et al. 2013). The 
existence of cancer stem cells perpetuates the notion that squamous cell tumors are composed of many different types of cells (Schober and Fuchs 2011). In other words, a tumor may not simply be one type of rapidly dividing cell type. Cancer stem cells are able to self-renew and differentiate thereby allowing them to sustain growth.

\section{Tumor Microenvironment}

The tumor microenvironment includes the stroma directly surrounding the tumor; it includes many different types of cells that can aid tumor growth and progression (Joyce and Fearon 2015). Tumor cells that are invasive have the ability to influence their microenvironment and make a network that is conducive to tumor growth and progression (Bauer, Su et al. 2010). The stroma contains an assortment of cells such as: inflammatory cells, endothelial cells, and fibroblasts. Cancer associated fibroblasts (CAF) differ from normal fibroblasts in that they express muscle-specific actin. How CAFs arise is not entirely clear. It seems as though they arise from fibroblasts that are already present in the tissue surrounding the tumor. TGF- $\beta$ and PDGF may be the paracrine factors responsible for inducing CAFs. The CAFs that reside in the tumor microenvironment are important because they may influence tumor cells directly (Bello, Vered et al. 2011). They have been shown experimentally to be present in the microenvironment of many OSCC tumors of the tongue. In another study they have been shown to be facilitators of invasion (Vered, Dayan et al. 2010). Additionally, they secrete proteases and enhance the presence of angiogenic factors; all of these facilitate tumor progression. 


\section{ZEB Expression in OSCC}

This project hypothesizes that there are different patterns of expression for the transcription factors ZEB1 and ZEB2 in oral squamous cell carcinoma as compared to healthy and dysplastic tissue. Furthermore, the expression patterns of ZEB1 and ZEB2 will be contrasted in order to get a better understanding of the interplay of these two factors in malignant transformation. The results indicate that there are changes in the way that ZEB1 and ZEB2 are expressed in controls and in the different histological grades of oral epithelial dysplasia, and squamous cell carcinoma. 


\section{CHAPTER II}

\section{MATERIALS AND METHODS}

Eighty de-indentified patient biopsy samples fixed in formalin and embedded in paraffin were identified by Dr. Brian S. Shumway from the Department of Hospital and Surgical Dentistry at the University of Louisville School of Dentistry (IRB: 13.0207). The collection comprises 10 samples of each major grade representing fibroma, mild dysplasia, moderate dysplasia, severe dysplasia, carcinoma in situ, well differentiated carcinoma, moderately differentiated carcinoma, and poorly differentiated carcinoma.

From each paraffin block, sections were cut at a thickness of five micrometers and placed in a deionized distilled water bath at $40^{\circ} \mathrm{C}$. After allowing the sections to float in the water for about thirty seconds, they were placed on Fischerbrand Superfrost Plus Microscope Slides. After the sections had properly been seated on the slides they were allowed to dry overnight in metal slide holders. Multiple slides were made for each paraffin block. Cut sections were stored at room temperature in slide boxes until ready to use.

The antibody procedures for these experiments used either a chromogenic detection method or a fluorescent detection method. The procedures for both are similar. First, slides were placed in an Autoblot Microhybridization Oven that was pre-heated to a 
temperature of $58^{\circ} \mathrm{C}$, for 30 minutes. After this time the slides were placed directly into mixed xylenes for 15 minutes to remove the melted paraffin. This was repeated twice in different washes of xylenes. The xylenes are rotated in a manner that the third position always contains fresh xylenes at the start of the assay. After the dewaxing steps, the slides were then incubated through graded alcohols and phosphate buffered saline (PBS) to rehydrate the tissue.

After rehydration was complete the slides are placed in pre-warmed sodium citrate buffer for heat induced epitope retrieval (HIER). The buffer had been warmed to $97{ }^{\circ} \mathrm{C}$ in an Autoblot Microhybridization Oven for one hour. This HIER method required the slides to be at this temperature for 30 minutes. After this step, excess PBS on the slides was removed using a Kim-wipe while ensuring that the tissue is not at risk for desiccation. Circles around the tissue were then drawn with a PAP barrier pen to prevent reagents from running off the slides. After the PAP circles were drawn the tissue was treated with $3 \%$ hydrogen peroxide for five minutes to block any endogenous peroxidase activity. The slides were then washed in $0.1 \%$ Triton-PBS for ten minutes in a slide box on an Orbital Shaker at speed 3. After washing, the tissue was blocked with normal goat serum (Vectastain ABC Kit, Vector Labs) for one hour. This again was washed for ten minutes prior to the antibody treatment. The rabbit polyclonal ZEB2 antibody used in all experiments was obtained from Abcam (Ab 25837) (Table 1). The immunogen for this antibody is within residues 1150 to the C-terminus; this area has low sequence similarity and would not result in cross-reactivity with ZEB1. Upon arrival, the antibody was aliquoted and stored at $-20^{\circ} \mathrm{C}$. Aliquots were thawed on ice prior to use. The primary antibody was diluted in $4 \%$ goat serum. Dilutions of 1:4000 to 1:5000 
were used on human tissues and allowed to incubate for two hours at room temperature. To ensure that samples did not dry out, the slides were surrounded by wet paper towels and covered to provide sufficient humidity.

After the primary antibody incubation, the slides were washed in three ten minute washes of $0.1 \%$ Triton-PBS. After the washes, the biotinylated secondary antibody (prepared per manufacturer's directions) from the Vectastain ABC kit was applied and allowed to incubate for 30 minutes. After one 10-minute wash, the $\mathrm{ABC}$ reagent from the kit was applied and subsequently washed off for ten minutes in $0.1 \%$ Triton PBS. After this final wash, the DAB Peroxidase (3,3'-diaminobenzidine, Vector Labs) chromogenic detector was applied for five minutes and then rinsed off with tap water until the water ran clear.

After the chromogen had been developed, the tissue was placed in deionized distilled water for one minute followed by dehydration in graded alcohols and xylenes. Slides were then mounted in Permount and coverslipped. After allowing the Permount to set, the slides were viewed using a Zeiss Axiocam MRc5 microscope (in the laboratory of Dr. Lisa Sandell). Slides were stored in slide boxes at room temperature.

In order to dual-label the cancer samples, a fluorescent labelled secondary antibody was used. The additional antibody was for pan-cytokeratin which allowed identification of cells of epithelial origin. For fluorescent antibody labelling the procedure following epitope retrieval was slightly altered. Fluorescent antibody labelling does not require treatment with hydrogen peroxide. After epitope retrieval the tissue was blocked for one hour with 10\% normal goat serum. The ZEB2 antibody (Abcam, Ab 25837) was diluted to a concentration of 1:100 and allowed to incubate at room 
temperature for two hours. Along with the ZEB2 antibody, the antibody for Pancytokeratin (Thermo Fischer MA1-8204, 1:500) was applied. After three ten-minute washes, the fluorescent secondary for ZEB2 (Alexa Fluor 488 goat anti-rabbit, 1:500) was applied for one hour in the dark at room temperature along with that for Pancytokeratin (Alexa Fluor 547 goat anti-mouse, 1:500). The slides were then washed in $0.1 \%$ Triton-PBS for 10 minutes. DAPI for nuclear staining (1:2000) was applied for five minutes and then washed once for 10 minutes with $0.1 \%$ Triton-PBS and once for 10 minutes with PBS. The slides were then mounted with VectaMount (Vector Labs) and coverslipped. The tissue was visualized with the Zeiss Axiocam MRc5 fluorescence microscope. Visualization was time sensitive due to the nature of fluorescent antibody labelling. Slides were stored in slide boxes in the $4^{0} \mathrm{C}$ refrigerator.

The fluorescent staining procedure outlined above was also implemented for the ZEB1 antibody (1:2000, Novus, NBP1-88845) raised against the central homeodomainlike region. A BLAST analysis was done in order to avoid cross reactivity with ZEB2. Samples were dual stained for ZEB1 and Pan-cytokeratin (same as above) and the same secondary fluorescent antibodies were used. 
Table 1: Antibodies Used

\begin{tabular}{|c|c|c|c|c|}
\hline Antibody & $\begin{array}{c}\text { Type of } \\
\text { Antibody }\end{array}$ & Manufacturer & Dilution & $\begin{array}{c}\text { Primary or } \\
\text { Secondary }\end{array}$ \\
\hline ZEB2 & $\begin{array}{c}\text { Rabbit } \\
\text { polyclonal }\end{array}$ & Abcam & $\begin{array}{c}1: 5000 \text { (DAB)- } \\
1: 200 \\
\text { (fluorescence) }\end{array}$ & Primary \\
\hline $\begin{array}{c}\text { Pan- } \\
\text { cytokeratin }\end{array}$ & $\begin{array}{c}\text { Mouse } \\
\text { monoclonal }\end{array}$ & Thermo-Fischer & $\begin{array}{c}1: 500 \\
\text { (fluorescence) }\end{array}$ & Primary \\
\hline $\begin{array}{c}\text { ZEB1 } \\
\text { polyclonal }\end{array}$ & Novus Biologics & $\begin{array}{c}1: 2000 \\
\text { (fluorescence) }\end{array}$ & Primary \\
\hline $\begin{array}{c}\text { Alexa-Fluor } \\
\text { 488 } \\
\text { (Goat anti- } \\
\text { rabbit) }\end{array}$ & $\begin{array}{c}\text { Goat } \\
\text { polyclonal } \\
\text { Alexa-Fluor } \\
546\end{array}$ & $\begin{array}{c}\text { Alexa-Fluor } \\
\text { (fluorescence) }\end{array}$ & Secondary \\
$\begin{array}{c}\text { Goat anti- } \\
\text { mouse }\end{array}$ & polyclonal & Alexa-Fluor & $\begin{array}{c}1: 500 \\
\text { (fluorescence) }\end{array}$ & Secondary \\
\hline $\begin{array}{c}\text { DAB } \\
\text { polyclonal }\end{array}$ & Vector Labs & $\begin{array}{c}\text { Not indicated by } \\
\text { manufacturer }\end{array}$ & Secondary \\
\hline
\end{tabular}




\section{Scoring Methodology}

In order to properly assess the epithelial tissues, some distinctions must be made regarding the structure of the oral epithelium. Histologically speaking, the tongue epithelium is keratinized stratified squamous epithelium (Bradley, Budnick et al. 2006). The architecture of the epithelium consists of a basal layer, a spinous layer, a spinous layer, and a granular layer (see Figure 2). The basal layer is adjacent to the basal lamina and stroma, and is where cells are proliferating. As cells become more differentiated they become more superficial. Eventually, the upper layers become enucleated and keratinized.

The tissue was scored for ZEB2 staining intensity as either negative $=0$, weak $=$ 1 , moderate $=2$, or strong $=3$. Since the pattern of ZEB2 staining was not strictly based on simply presence or absence, a qualitative assessment needed to be made in addition to intensity. The location, nuclear or cytosolic, is also a factor that was included in order to assess the expression pattern of ZEB2. Furthermore, scoring recorded whether or not the expression was restricted to a particular area or found throughout the epithelial layers. The latter was described as ubiquitous whereas the former was described as restricted basal, restricted spinous, or restricted granular layer (Woolgar 2006). Furthermore, the proportion of cells staining was quantified as 0 if less than $25 \%$ of cells were stained within the epithelum, 1 if $25-50 \%$ were stained, 2 if 50-75\% were stained, and 3 if over $75 \%$ of cells were stained. 


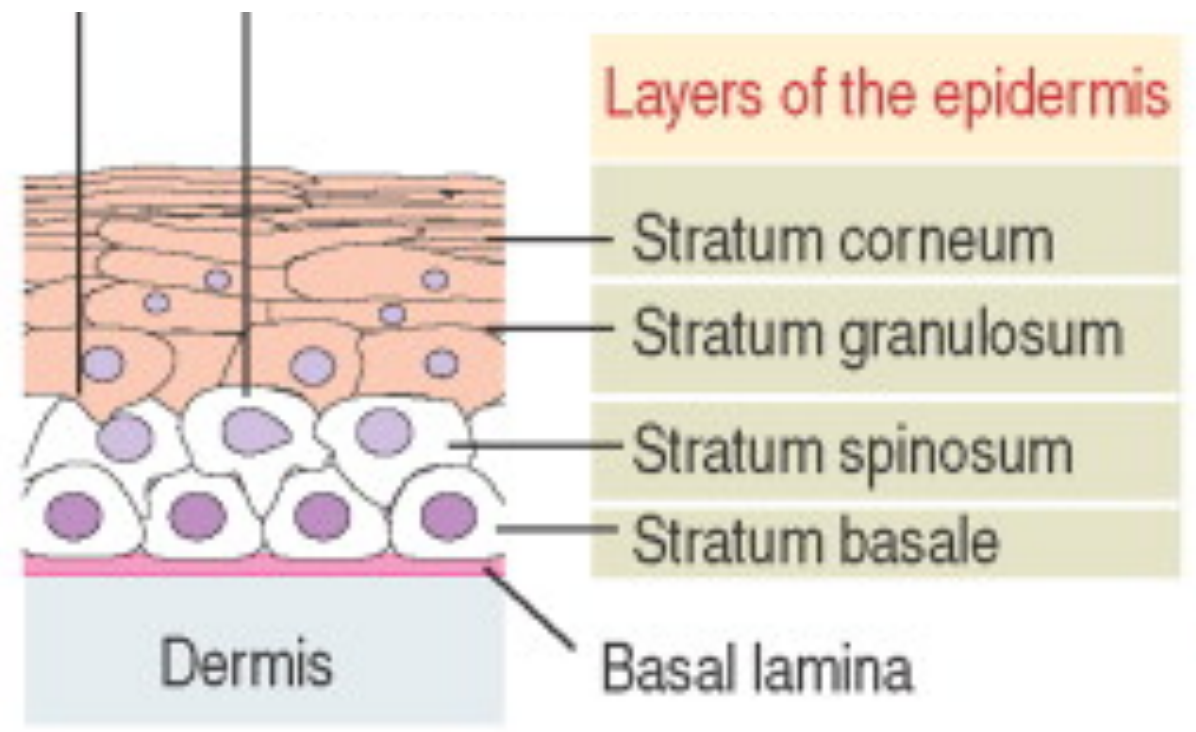

Figure 2: Epithelial tissue layers. The stratum basale is the layer in which stem cells reside and this is where cells are actively dividing. As the cells go from the basal layer to the stratum corneum they become more differentiated. The most upper layers may or may not be keratinized; this depends on the type of epithelium. In the oral cavity there are both ortho-keratinized and para-keratinized types epithelium. This project utilizes tissues obtained from para- keratinized epithelium. Figure adapted from Histology \& Cell Biology: An Introduction to Pathology (Kierszenbaum and Tres 2015). 
In the higher grades of carcinoma the epithelial layers became less discernable from the surrounding connective tissue and the cancer cells. To ascertain which cells were of the epithelial phenotype, the samples were labelled with an antibody for pancytokeratin. Those cells staining positive for pan-cytokeratin were considered either as epithelial cells or epithelial derived cells. Those that were pan-cytokeratin negative were considered stromal immune cells or connective tissue cells. This helped determine in which cells ZEB2 expression was taking place.

Once samples were stained they were imaged with either the AxioCam M5c or the Leica SP8 confocal microscope. The AxioCam M5c was used for light microscopy and fluorescence. The confocal microscope allowed sequential fluorescence scanning in addition to Z-stacks which allowed greater detail to be observed.

\section{Statistical Analysis}

In order to assess the differences in expression across the different histological grades, the Kruskal-Wallis test for non-parametric ordinal data was utilized. This test is an analysis of variance (ANOVA) for ordinal data. This was followed by Dunn's Multiple Comparison to identify which individual groups differed. The analysis was done using the Prism 5 software manufactured by the GraphPad company. 


\section{CHAPTER III}

\section{RESULTS}

There were eight different histological diagnoses were used for ZEB2 and ZEB1 staining. The fibroma samples served as the control since fibromas are not considered to have pathologic epithelia alterations and generally show normal epithelial maturation. The fibroma samples were used to establish the baseline expression. The pathological samples progressed from mild dysplasia, moderate dysplasia, and severe dysplasia, carcinoma in situ, to well differentiated carcinoma, moderately differentiated carcinoma, and poorly differentiated carcinoma.

\section{Fibroma}

The ten fibroma samples that were stained for ZEB2 showed positive ZEB2 staining. All stained positive for ZEB2 in the nuclei all along the basal layer of epithelium. This is consistent with a role for ZEB2 in relatively undifferentiated

proliferative cells. Nine samples displayed a restricted staining pattern, which is defined as the presence of ZEB2 in one layer (basal, spinous, or suprabasal). These samples showed strong ZEB2 nuclear staining along the basal layer, with weak cytosolic staining of the cells of the spinous layer. One sample displayed very weak and very restricted staining. Furthermore, the most superficial keratinized layers showed a lack of staining for ZEB2 in all ten samples. The results of ZEB2 immunostaining for each sample is described below and summarized in Table 2. Figure 3 shows a representative sample of the most frequently occurring staining patterns. 
All ten samples of fibroma stained positively. The majority of the cases displayed restricted expression with moderate staining through about two-thirds of the length of the rete ridges. This expression pattern was seen in seven cases. There were no instances of negative staining in any of the samples. Nine of the ten fibroma samples displayed ZEB2 expression only in the basal and spinous layers. In the remaining sample, there was only very restricted staining in the basal layer. Overall, the proportion of cells staining positively for ZEB2 was quite low. It should also be noted that in the area below the basal lamina, there was strong nuclear ZEB2 staining in the underlying connective tissue. These cells are not noticeably fibroblastic in shape, and they are possibly tissue-resident immune cells. 
Table 2: ZEB2 Expression Fibroma Samples Summary

\begin{tabular}{|c|c|c|c|c|c|}
\hline Sample & Cells & Location & Strength & Pattern & Proportion \\
\hline \multirow[t]{2}{*}{$\mathrm{F} 1$} & Basal & Nuclear & 2 & \multirow[t]{2}{*}{$\mathrm{R}$} & \multirow[t]{2}{*}{0} \\
\hline & Spinous & Cytosol & 1 & & \\
\hline \multirow[t]{2}{*}{$\mathrm{F} 2$} & Basal & Nuclear & 3 & \multirow[t]{2}{*}{$\mathrm{R}$} & \multirow[t]{2}{*}{1} \\
\hline & Spinous & Cytosol & 2 & & \\
\hline \multirow[t]{2}{*}{ F3 } & Basal & Nuclear & 3 & \multirow[t]{2}{*}{$\mathrm{R}$} & \multirow[t]{2}{*}{0} \\
\hline & Spinous & Cytosol & 2 & & \\
\hline \multirow[t]{2}{*}{$\mathrm{F} 4$} & Basal & Nuclear & 3 & \multirow{2}{*}{$\mathrm{R}$} & \multirow[t]{2}{*}{1} \\
\hline & Spinous & Cytosol & 2 & & \\
\hline \multirow[t]{2}{*}{ F5 } & Basal & Nuclear & 1 & \multirow[t]{2}{*}{$\mathrm{R}$} & \multirow[t]{2}{*}{0} \\
\hline & Spinous & Cytosol & 2 & & \\
\hline F6 & Basal & Nuclear & 1 & VR & 0 \\
\hline \multirow[t]{2}{*}{ F7 } & Basal & Nuclear & 1 & \multirow[t]{2}{*}{$\mathrm{R}$} & \multirow[t]{2}{*}{0} \\
\hline & Spinous & Cytosol & 1 & & \\
\hline \multirow[t]{2}{*}{ F8 } & Basal & Nuclear & 1 & \multirow[t]{2}{*}{$\mathrm{R}$} & \multirow[t]{2}{*}{0} \\
\hline & Spinous & Cytosol & 1 & & \\
\hline \multirow[t]{2}{*}{ F9 } & Basal & Nuclear & 3 & \multirow[t]{2}{*}{$\mathrm{R}$} & \multirow[t]{2}{*}{1} \\
\hline & Spinous & Cytosol & 2 & & \\
\hline \multirow[t]{2}{*}{ F10 } & Basal & Nuclear & 2 & \multirow[t]{2}{*}{$\mathrm{R}$} & \multirow[t]{2}{*}{0} \\
\hline & Spinous & Cytosol & 1 & & \\
\hline
\end{tabular}

Table 2: This table shows all the data collected for the histological grade of fibroma. VR indicates a very restricted pattern of staining. VR is limited to one layer of cells, more specifically, the basal cells. $\mathrm{R}$ indicates a restricted pattern. The $\mathrm{R}$ pattern goes beyond the basal layer into the spinous layer. 

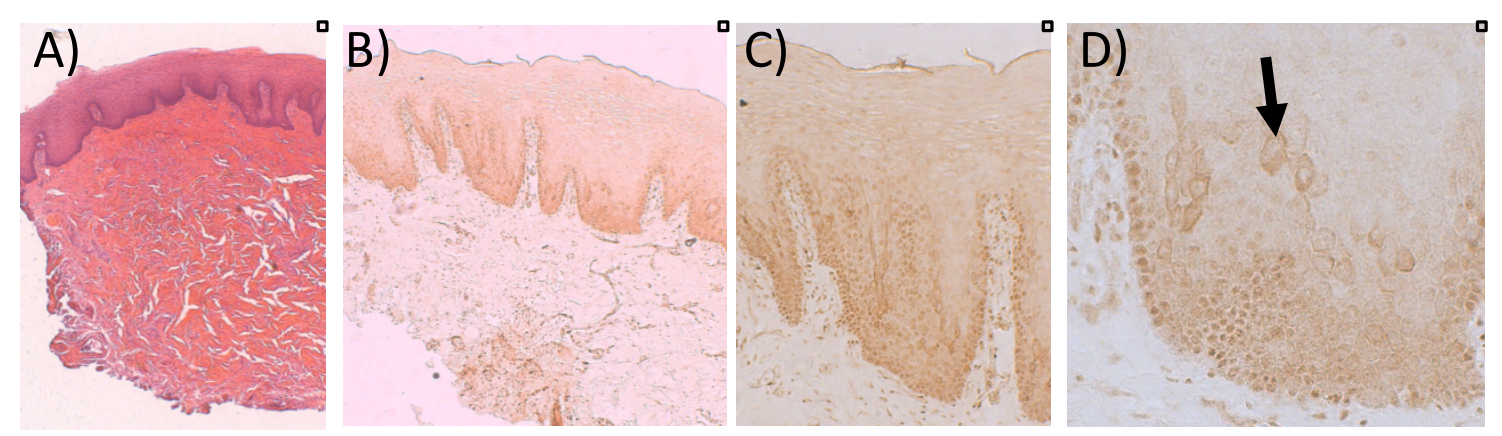

Figure 3: ZEB2 Expression in Fibroma. A) Routine power H\&E appearance (40X). B) DAB stained labelled for ZEB2; grossly the appearance of a band of ZEB2 staining is evident in the basal layer. The pattern is seen consistently in the basal layer of the rete ridges. C) In this $20 \mathrm{X}$ image, it clearly shows dark staining nuclei along with some cells expressing in the cytosol in the spinous layers. D) In this $400 \mathrm{X}$ image, there is a clear nucleus of the cell surrounded by brown cytosol (black arrow) indicating strong cytosolic expression. This occurs in a few cells and the surrounding cells of the basal layer displaying nuclear expression. 


\section{Mild Dysplasia (LDy)}

In nine of the ten samples of mild dysplasia there was positive staining for ZEB2. In the samples that did stain, there was a general trend of nuclear staining in the basal layer with cytosolic staining apparent in the spinous layer. For five of the ten mild dysplasia samples there was moderate to strong staining in the basal and spinous layers. The staining in the basal layer was nuclear while in the spinous the staining was cytosolic.

Three of the samples display restricted ZEB2 staining, whereas two of the samples show ubiquitous staining. Furthermore, there was one sample that did not stain at all for ZEB2. In these samples, ZEB2 stained either in the nucleus only of certain cells, the nucleus and cytosol in the same cell, or it did not stain at all. Most of the samples stained both nuclear and cytosolic. These results are summarized in Table 3 and the most representative samples are shown in Figure 4. 
Table 3: ZEB2 Expression In Mild Dysplasia (LDy)

\begin{tabular}{|c|c|c|c|c|c|}
\hline Sample & Cells & Location & Strength & Pattern & Proportion \\
\hline \multirow[t]{2}{*}{ LDy1 } & Basal & Nuclear & 2 & \multirow[t]{2}{*}{$\mathrm{R}$} & \multirow[t]{2}{*}{1} \\
\hline & Spinous & Cytosol & 1 & & \\
\hline \multirow[t]{2}{*}{ LDy2 } & Basal & Nuclear & 1 & \multirow[t]{2}{*}{$\mathrm{R}$} & \multirow[t]{2}{*}{2} \\
\hline & Spinous & Cytosol & 1 & & \\
\hline \multirow[t]{2}{*}{ LDy3 } & Basal & Nuclear & 3 & \multirow[t]{2}{*}{$\mathrm{R}$} & \multirow[t]{2}{*}{1} \\
\hline & Spinous & & 3 & & \\
\hline LDy4 & Basal & Nuclear & 2 & & 1 \\
\hline \multirow[t]{2}{*}{ LDy5 } & Basal & Nuclear & 3 & \multirow{2}{*}{$\frac{\mathrm{VR}}{\mathrm{R}}$} & \multirow[t]{2}{*}{1} \\
\hline & Spinous & Cytosol & 1 & & \\
\hline \multirow[t]{2}{*}{ LDy6 } & Basal & Nuclear & 2 & \multirow[t]{2}{*}{$\mathrm{R}$} & \multirow[t]{2}{*}{1} \\
\hline & Spinous & Cytosol & 1 & & \\
\hline \multirow[t]{2}{*}{ LDy7 } & Basal & Nuclear & 3 & \multirow[t]{2}{*}{$\mathrm{R}$} & \multirow[t]{2}{*}{1} \\
\hline & Spinous & Cytosol & 2 & & \\
\hline \multirow[t]{2}{*}{ LDy8 } & Basal & Nuclear & 2 & \multirow[t]{2}{*}{$\mathrm{R}$} & \multirow[t]{2}{*}{0} \\
\hline & Spinous & Cytosol & 1 & & \\
\hline LDy9 & 0 & & & & \\
\hline \multirow[t]{2}{*}{ LDy10 } & Basal & Nuclear & 2 & \multirow[t]{2}{*}{$\mathrm{R}$} & \multirow[t]{2}{*}{2} \\
\hline & Spinous & Cytosol & 2 & & \\
\hline
\end{tabular}

Table 3: This table shows the data collected for mild dysplasia. VR indicates staining to one cell layer, while $\mathrm{R}$ indicates staining in the basal layer as well as the spinous layer. 

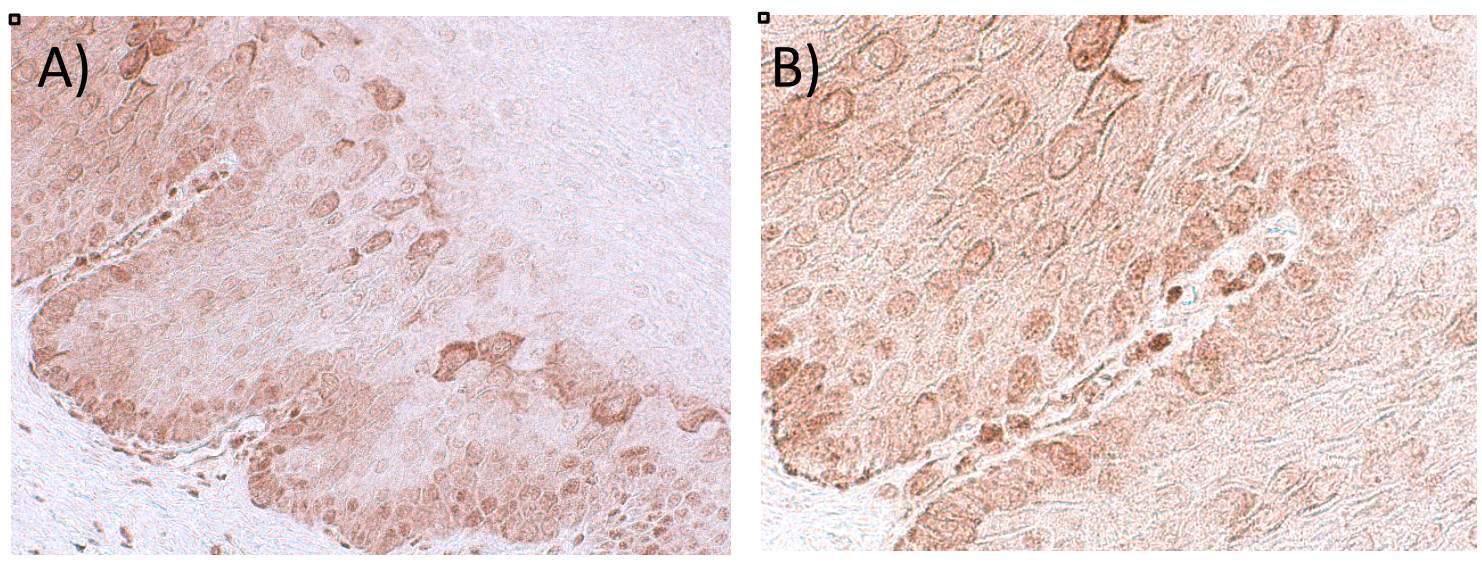

Figure 4: ZEB2 Expression in Mild Dysplasia. A) In this 200X image there is clear nuclear staining in the basal layer as well as scattered cytosolic staining in the spinous layer. B) In this $400 \mathrm{X}$ image ZEB2 staining is largely restricted to the nucleus in the basal layer. Adjacent to the rete ridges the underlying connective tissue can be seen. Cells in the connective tissue also stain positively for ZEB2 in the nucleus (400X). 


\section{Moderate Dysplasia (MDy)}

In moderate dysplasia the samples all stained positively for ZEB2. The three staining patterns that were observed include nuclear only, cytosolic only, and nuclear and cytosolic. Five of the ten samples detected ZEB2 in the nucleus in either the basal or spinous layers. There was not any evidence of staining in the upper keratinzed layers. The remainder of the samples were stained either only in the cytosol or both nuclear and cytosolic. These data are summarized in Table 4, and Figure 5 shows a representative example of staining for moderate dysplasia. 
Table 4: ZEB2 Expression Summary Moderate Dysplasia

\begin{tabular}{|c|c|c|c|c|c|}
\hline Sample & Cells & Location & Strength & Pattern & Proportion \\
\hline MDy1 & Basal & Nuclear & 2 & VR & 1 \\
\hline \multirow[t]{2}{*}{ MDy2 } & Basal & Nuclear & 3 & \multirow[t]{2}{*}{$\mathrm{R}$} & \multirow[t]{2}{*}{2} \\
\hline & Spinous & Cytosol & 2 & & \\
\hline \multirow[t]{2}{*}{ MDy3 } & Basal & Nuclear & 2 & \multirow[t]{2}{*}{$\mathrm{R}$} & \multirow[t]{2}{*}{1} \\
\hline & Spinous & & 2 & & \\
\hline \multirow[t]{2}{*}{ MDy4 } & Basal & Nuclear & 3 & \multirow[t]{2}{*}{$\mathrm{R}$} & \multirow[t]{2}{*}{1} \\
\hline & Spinous & $\begin{array}{c}\text { Nuclear }+ \\
\text { Cytosol }\end{array}$ & 3 & & \\
\hline \multirow[t]{2}{*}{ MDy5 } & Basal & Nuclear & 1 & \multirow[t]{2}{*}{$\mathrm{R}$} & \multirow[t]{2}{*}{1} \\
\hline & Spinous & Cytosol & 1 & & \\
\hline MDy6 & Spinous & Cytosol & 1 & VR & 1 \\
\hline MDy7 & Basal & Nuclear & 3 & $\mathrm{R}$ & 1 \\
\hline \multirow[t]{3}{*}{ MDy8 } & Basal & Nuclear & 3 & \multirow[t]{3}{*}{$\mathrm{U}$} & \multirow[t]{3}{*}{2} \\
\hline & Spinous & Cytosol & 3 & & \\
\hline & Keratinized & Nuclear & 2 & & \\
\hline MDy9 & Spinous & Cytosol & 3 & VR & 1 \\
\hline \multirow[t]{3}{*}{ MDy10 } & Basal & Nuclear & 2 & \multirow[t]{3}{*}{$\mathrm{R}$} & \multirow[t]{3}{*}{2} \\
\hline & Spinous & Cytosol & 3 & & \\
\hline & Keratinized & Nuclear & 2 & & \\
\hline
\end{tabular}

Table 4: This data for moderate dysplasia are shown in this table. The VR pattern is restricted to the basal layer, $\mathrm{R}$ is staining in the basal and spinous layer while $\mathrm{U}$ indicates ubiquitous staining with staining seen throughout the thickness of the epithelium. 


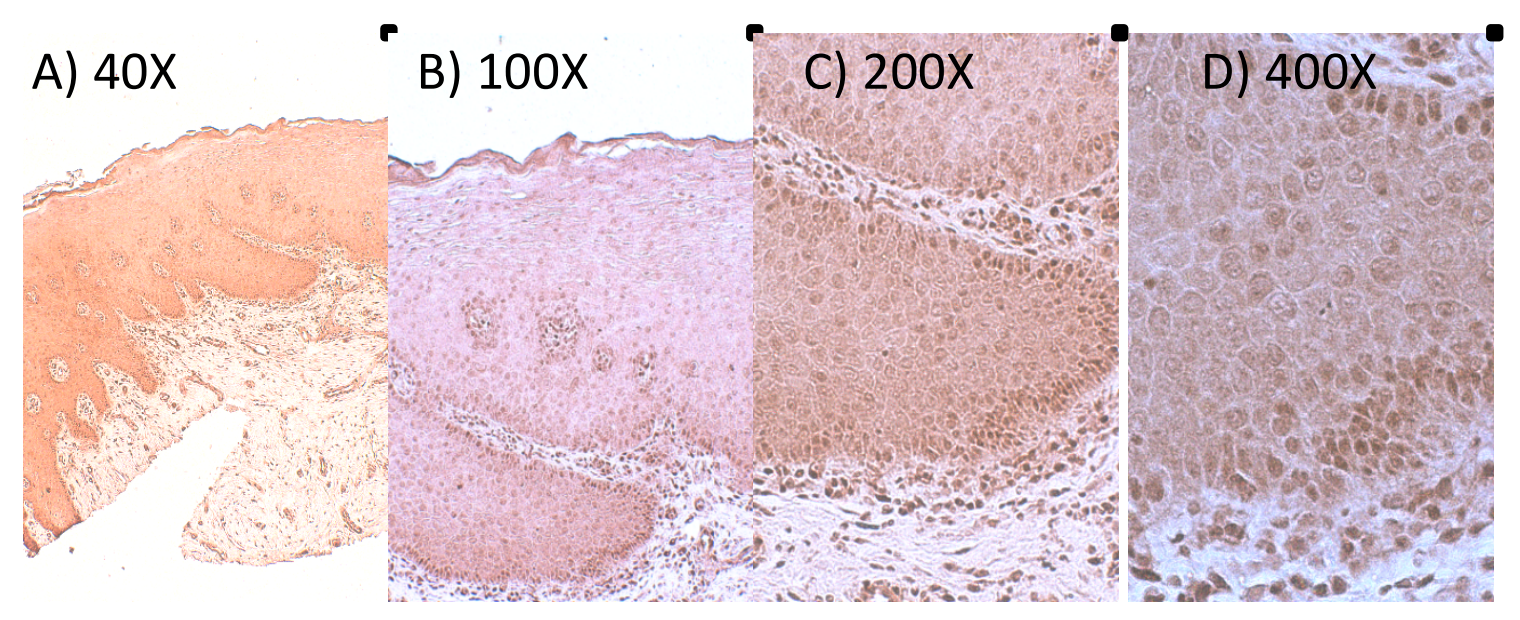

Figure 5: ZEB2 Expression in Moderate Dysplasia. A) In this low power image there is broad, apparently non-specific staining of the DAB, at this magnification it looks as though the staining is all over and non-specific. B) Higher power shows a more punctate pattern, but still not high enough to discern where exactly the staining is occurring. C) At 200X the appearance of nuclear staining in the basal layer. D) There is the appearance of strong nuclear staining and few cells showing faint cytoplasmic staining (400X) 


\section{ZEB2 Expression Severe Dysplasia}

Moderate dysplasia can progress to severe dysplasia. The difference between moderate and severe dysplasia is the degree of involvement of the epithelial tissue; in severe dysplasia over two-thirds of the epithelium displays abnormalities (Warnakulasuriya, Reibel et al. 2008). We had ten samples of severe dysplasia that we subjected to antibody staining with ZEB2.

Overall, there is a presence of strong cytosolic expression throughout the spinous layers. This pattern was observed in five out of the ten samples. In one sample there was not any presence of ZEB2 staining. In four of the ten samples there was ZEB2 expression throughout the thickness of the epithelium and therefore unrestricted. These results are summarized in Table 5 and representative samples are displayed in Figure 6. 
Table 5: ZEB2 Expression in Severe Dysplasia Summary

\begin{tabular}{|c|c|c|c|c|c|}
\hline Sample & Cells & Location & Strength & Pattern & Proportion \\
\hline \multirow[t]{2}{*}{ SDy1 } & Basal & Nuclear & 1 & \multirow[t]{2}{*}{$\mathrm{R}$} & \multirow[t]{2}{*}{1} \\
\hline & Spinous & Cytosolic & 2 & & \\
\hline \multirow[t]{2}{*}{ SDy2 } & Basal & Nuclear & 2 & \multirow[t]{2}{*}{$\mathrm{R}$} & \multirow[t]{2}{*}{3} \\
\hline & Spinous & Cytosolic & 3 & & \\
\hline \multirow{3}{*}{ SDy3 } & Basal & Nuclear & 1 & \multirow[t]{3}{*}{$\mathrm{U}$} & \multirow[t]{3}{*}{3} \\
\hline & Spinous & Cytosolic & 3 & & \\
\hline & Keratinized & Nuclear & 2 & & \\
\hline \multirow[t]{2}{*}{ SDy4 } & Spinous & Cytosolic & 2 & \multirow[t]{2}{*}{$\mathrm{R}$} & \multirow[t]{2}{*}{1} \\
\hline & Keratinized & Nuclear & 2 & & \\
\hline SDy5 & & & 0 & & \\
\hline \multirow[t]{2}{*}{ SDy6 } & Basal & Nuclear & 1 & \multirow[t]{2}{*}{$\mathrm{R}$} & \multirow[t]{2}{*}{2} \\
\hline & Spinous & Cytosolic & 2 & & \\
\hline \multirow[t]{2}{*}{ SDy7 } & Basal & Nuclear & 1 & \multirow[t]{2}{*}{$\mathrm{R}$} & \multirow[t]{2}{*}{2} \\
\hline & Spinous & Cytosolic & 2 & & \\
\hline \multirow[t]{3}{*}{ SDy8 } & Basal & Nuclear & 2 & \multirow[t]{3}{*}{$\mathrm{U}$} & \multirow[t]{3}{*}{2} \\
\hline & Spinous & Nuclear & 3 & & \\
\hline & Keratinized & Nuclear & 2 & & \\
\hline \multirow[t]{2}{*}{ SDy9 } & Basal & Nuclear & 2 & \multirow[t]{2}{*}{$\mathrm{R}$} & \multirow[t]{2}{*}{3} \\
\hline & Spinous & Nuclear & 2 & & \\
\hline SDy10 & Basal & Nuclear & 2 & $\mathrm{R}$ & 3 \\
\hline
\end{tabular}

Table 5: Data shown the results for severe dysplasia. The staining patterns were either $\mathrm{R}$ (restricted) or $\mathrm{U}$ (ubiquitous). 


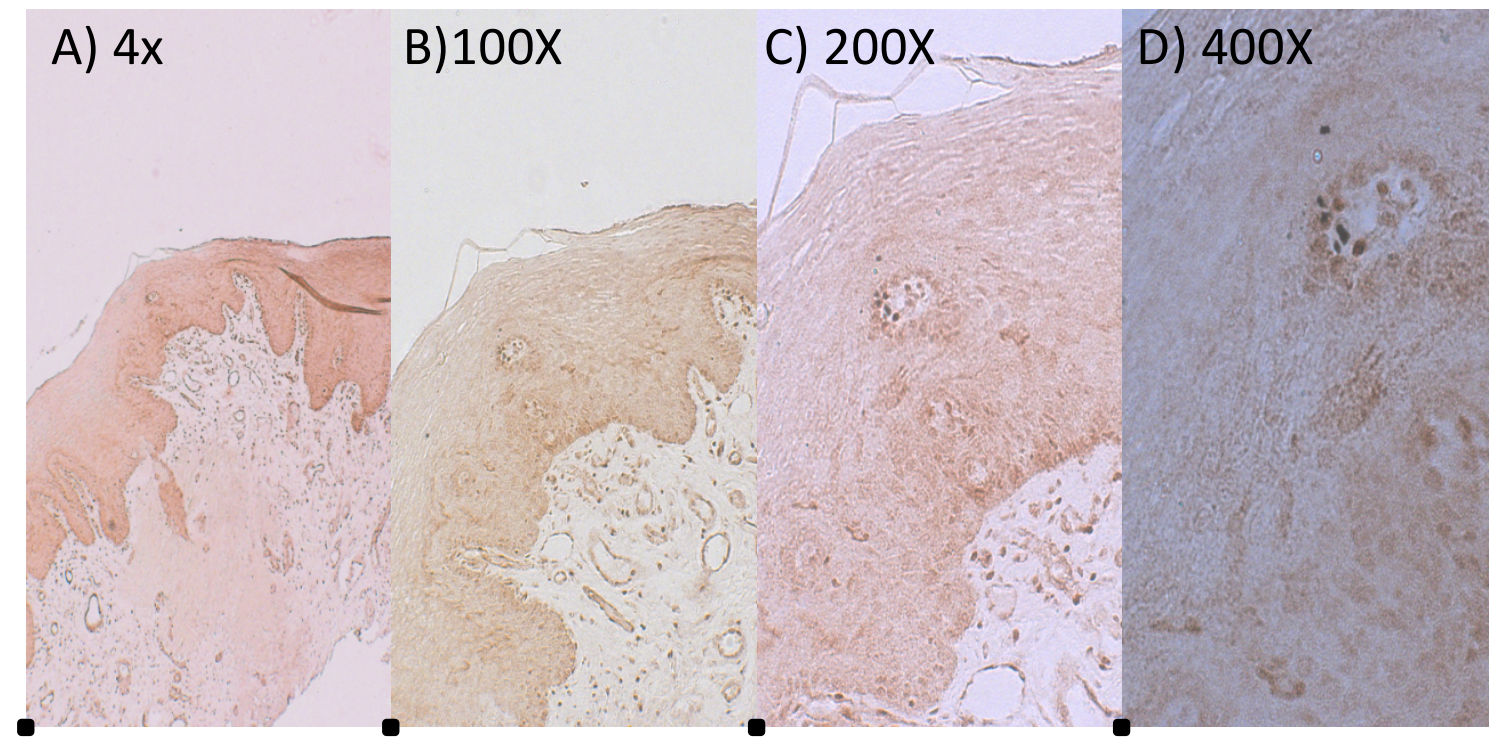

Figure 6: ZEB2 Expression Severe Dysplasia A) Moderate ZEB2 staining of the epithelium and not very frank staining in the underlying connective tissue. B) This image shows more clearly the appearance of some nuclei in the basal layer staining positively for ZEB2; this staining seems limited to the basal layer. There is also the presence of a band of staining in the spinous layer. C) The band of staining the spinous layer is clearly cytosolic expression (200X). D) A higher magnification highlights the presence of the nuclear staining basal layer and the cytosolic staining in the spinous layer (400X). 


\section{Carcinoma in Situ (CIS)}

After the severely dysplastic stage, the lesion may progress to carcinoma in situ (CIS). CIS is characterized by the loss of organization in the epithelial tissues

(Warnakulasuriya, Reibel et al. 2008). As with the dysplasia samples, there were ten CIS samples provided to us and subjected to staining with ZEB2.

In seven of the ten samples there was unrestricted ZEB2 staining present; the pattern of staining was both nuclear and cytosolic. Of the remaining three, there was one instance of negative staining, and two that had restricted staining. These results are summarized in Table 6, and Figure 7 shows a representative sample. The most striking observation in this category as a whole is the presence of a broad band of cytosolic staining. This grade is typified by extensive cytosolic staining in the spinous layer. While staining is present in the nuclei of the basal cells adjacent to the connective tissue, this is distinctly weaker than in the spinous layers of cells. This is the first grade with extensive ZEB2 staining across the middle portion of the epithelium. 
Table 6: ZEB2 Expression Summary Carcinoma In Situ

\begin{tabular}{|c|c|c|c|c|c|}
\hline Sample & Cells & Location & Strength & Pattern & Proportion \\
\hline \multirow[t]{2}{*}{ CIS1 } & Basal & Nuclear & 2 & \multirow[t]{2}{*}{$\mathrm{R}$} & \multirow[t]{2}{*}{3} \\
\hline & Spinous & Nuclear & 2 & & \\
\hline \multirow[t]{3}{*}{ CIS2 } & Basal & Nuclear & 1 & \multirow[t]{3}{*}{$\bar{U}$} & \multirow[t]{3}{*}{3} \\
\hline & Spinous & Cytosolic & 2 & & \\
\hline & Keratinized & Nuclear & 1 & & \\
\hline \multirow[t]{3}{*}{ CIS3 } & Basal & Nuclear & 2 & \multirow[t]{3}{*}{$\mathrm{U}$} & \multirow[t]{3}{*}{3} \\
\hline & Spinous & Cytosolic & 2 & & \\
\hline & Keratinized & Nuclear & 2 & & \\
\hline \multirow[t]{2}{*}{ CIS4 } & Basal & Nuclear & 2 & \multirow[t]{2}{*}{$\mathrm{R}$} & \multirow[t]{2}{*}{2} \\
\hline & Spinous & Cytosolic & 3 & & \\
\hline \multirow[t]{3}{*}{ CIS5 } & Basal & Nuclear & 3 & \multirow[t]{3}{*}{$\mathrm{U}$} & \multirow[t]{3}{*}{2} \\
\hline & Spinous & Nuclear & 2 & & \\
\hline & Keratinized & Nuclear & 1 & & \\
\hline \multirow[t]{2}{*}{ CIS6 } & Basal & Nuclear & 1 & \multirow[t]{2}{*}{$\mathrm{R}$} & \multirow[t]{2}{*}{3} \\
\hline & Spinous & Cytosolic & 2 & & \\
\hline CIS7 & & & 0 & & \\
\hline CIS8 & Spinous & Cytosolic & 1 & VR & 3 \\
\hline \multirow[t]{2}{*}{ CIS9 } & Spinous & Cytosolic & 2 & \multirow[t]{2}{*}{$\mathrm{R}$} & \multirow[t]{2}{*}{3} \\
\hline & Keratinized & Nuclear & 2 & & \\
\hline \multirow[t]{3}{*}{ CIS10 } & Basal & Nuclear & 1 & \multirow[t]{3}{*}{$\mathrm{U}$} & \multirow[t]{3}{*}{3} \\
\hline & Spinous & Cytosolic & 3 & & \\
\hline & Keratinized & Nuclear & 1 & & \\
\hline
\end{tabular}

Table 6: This table shows the result for carcinoma in situ. The three staining patterns that were seen include very restricted (VR), restricted (R), or ubiquitous (U). 

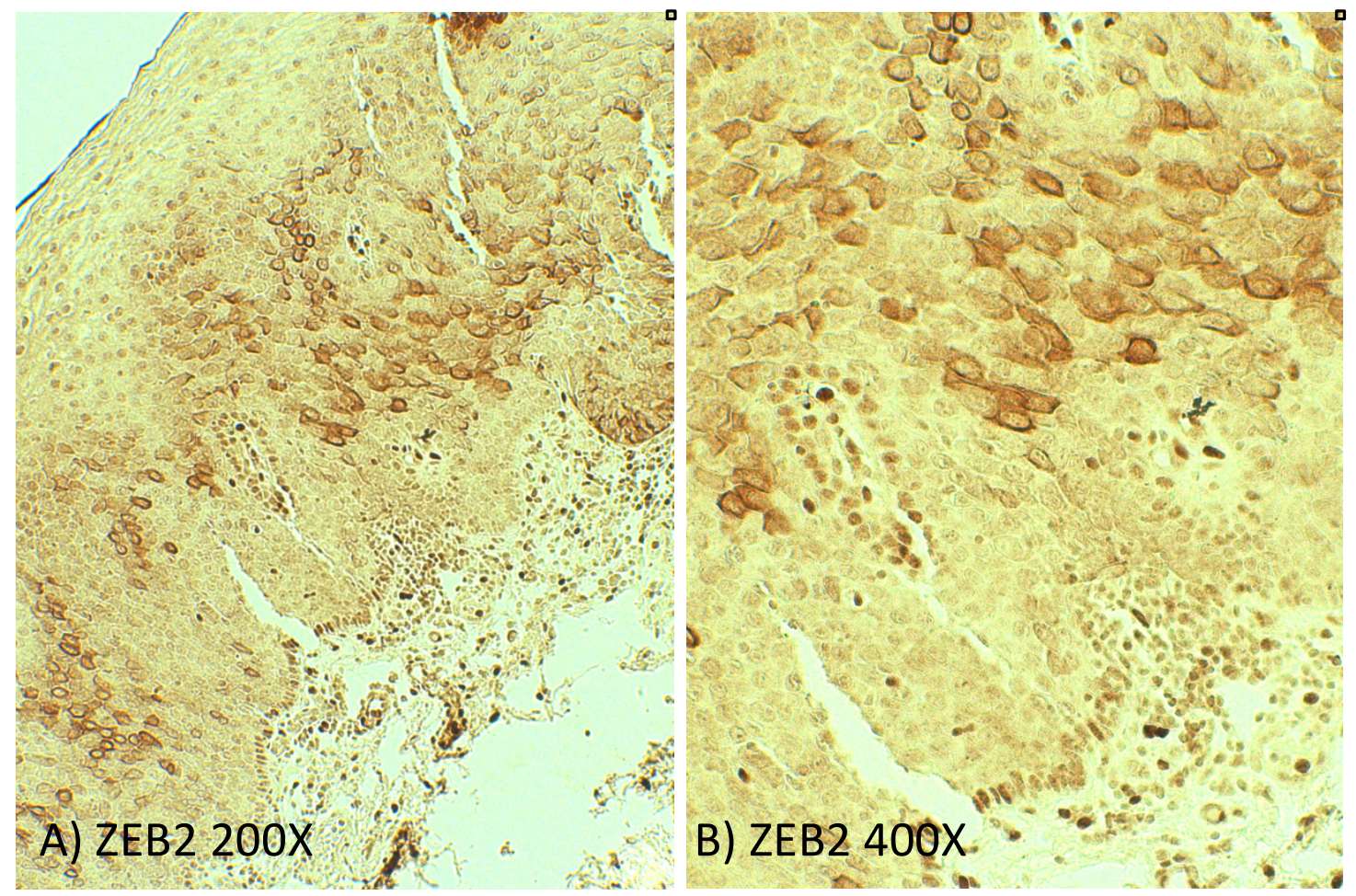

Figure 7: ZEB2 Expression in Carcinoma in Situ. A) The 200X image on the shows one line of nuclei staining positive for ZEB2 in the basal layer. There is also an apparent broad band of strong cytosolic expression see in the spinous layer. B) The higher power on the right shows this detail more clearly. 


\section{Well Differentiated Carcinoma (WC)}

The stage after CIS is well differentiated carcinoma. In this early grade of carcinoma, the tissue architecture is not entirely lost and there are certain characteristics that are present such as keratin pearls (Kumar, Abbas et al. 2013). There is a shift in the staining pattern of ZEB2 as compared to the dysplasia and CIS samples. In six of the ten well differentiated carcinoma samples there was negative staining for ZEB2. In the remaining four samples there was moderate expression of ZEB2 mostly restricted to epithelial tissue.

As compared to CIS, there are pronounced changes in ZEB2 expression in well differentiated carcinoma. ZEB2 in most instances was cytosolic and also fewer cells are expressing ZEB2. Furthermore, the expression of ZEB2 was weak to moderate. Cytosolic ZEB2 expression was mostly seen in cells at the edges of the keratin pearls. ZEB2 positive staining identified a distinct subset of cells closely adjacent to the keratin pearls as they are seen on the periphery of the keratin pearls. These results are summarized in Table 7, and Figure 8 shows an example of positive ZEB2 staining. 
Table 7: ZEB2 Expression Summary Well Differentiated Carcinoma

\begin{tabular}{|c|c|c|}
\hline Sample & Strength & Location \\
\hline WC1 & 0 & N/A \\
\hline WC2 & 0 & N/A \\
\hline WC3 & 0 & N/A \\
\hline WC4 & 2 & N/A \\
\hline WC5 & 0 & Cytosolic \\
\hline WC6 & 2 & N/A \\
\hline WC7 & 0 & N/A \\
\hline WC8 & 0 & Nuclear \\
\hline WC9 & 2 & Nuclear \\
\hline WC10 & 2 & \\
\hline
\end{tabular}

Table 7: Well differentiated staining pattern data shown in this table. The ZEB2 expression goes down in this grade of carcinoma. 

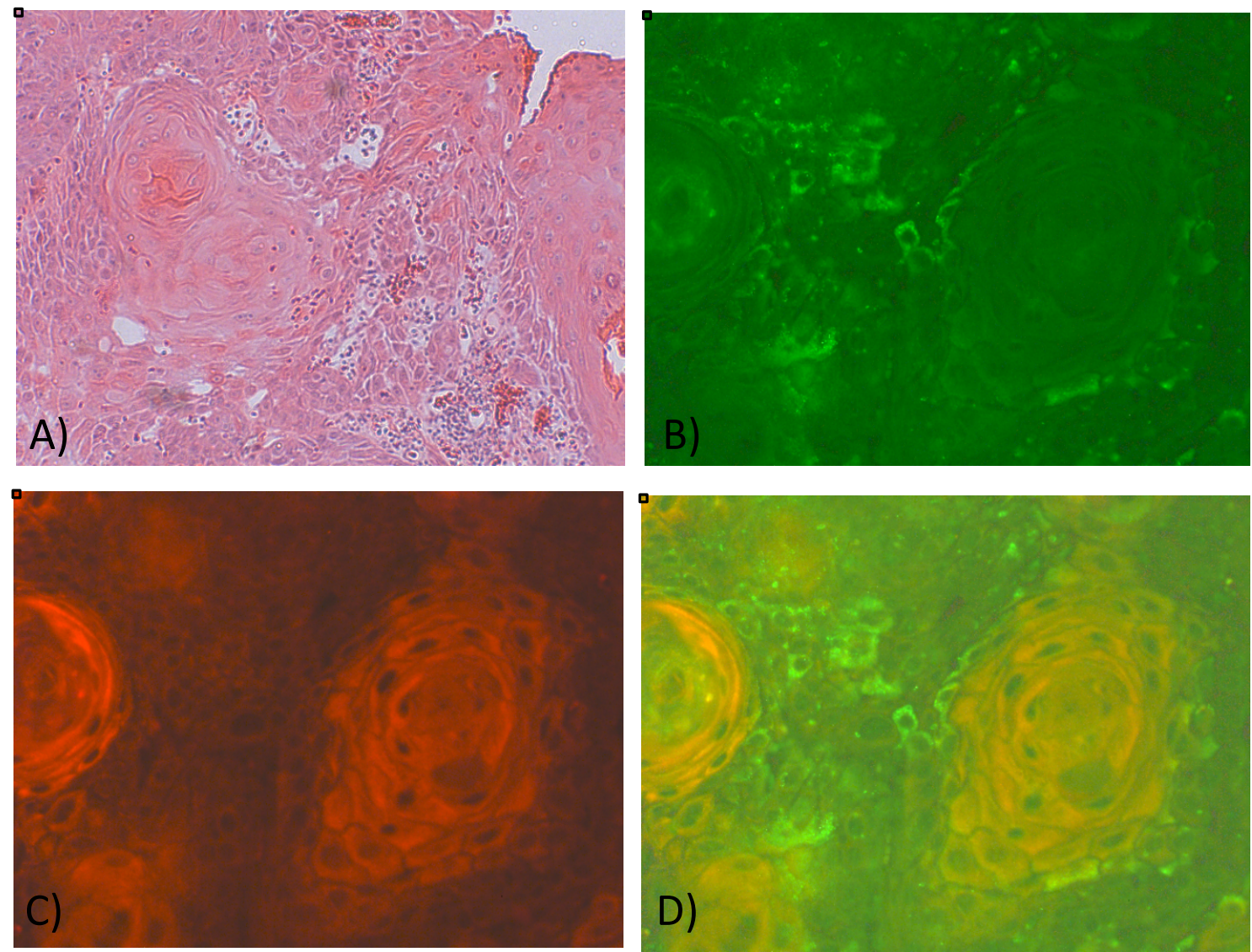

Figure 8: ZEB2 Expression in Well Differentiated Carcinoma. A) Low power H\&E showing diagnostic keratin pearls for well differentiated carcinoma. B) This fluorescent stained image (40X) is showing strong cytosolic expression of ZEB2 (green) on the periphery of cells showing pan-cytokeratin expression C) The pan-cytokeratin staining (red) confirms that these cells are of epithelial origin. D) This image is an overlay showing that the staining is on the periphery of the pan-cytokeratin positive cells 


\section{Moderately Differentiated Carcinoma (Mdc)}

Once the carcinoma has progressed beyond the well differentiated stage, it is difficult to discern the layers of the epithelium. For the grades beyond well differentiated carcinoma, the fluorescent staining was more appropriate since it allowed the staining of pan-cytokeratin. One hallmark of carcinoma cells is that they must be pan-cytokeratin positive to be considered of epithelial origin. The pan-cytokeratin was the determining factor in which cells were considered to be cancerous, all other cells were considered to be stromal cells. Since the organization of the epithelial tissue was no longer intact, it was difficult to assign patterns in this grade, as well as in poorly differentiated carcinoma.

As the carcinoma loses differentiation in moderately differentiated carcinoma cells continued to express ZEB2 in the cytosol, but fewer than $25 \%$ of cells were expressing ZEB2. In this grade there was an increased amount of exclusively cytosolic expression, as compared to a mixture of nuclear and cytosolic expression. Cells expressed ZEB2 weakly or moderately. As was observed in well-differentiated carcinoma, cells that were expressing ZEB2 were located on the periphery of the keratin pearls. As with well differentiated carcinoma, there were instances of negative ZEB2 staining; this occurred in half of the samples. The other half showed nuclear and cytosolic staining. So, overall in this grade, there was decreased number of cells expressing ZEB2, and only a rare scattering of cells with nuclear ZEB2 staining. Table 8 summarizes these results and Figure 9 shows an example of positively stained ZEB2 moderately differentiated carcinoma samples. 
Table 8: ZEB2 Expression Summary in Moderately Differentiated Carcinoma

\begin{tabular}{|c|c|c|}
\hline Sample & Strength & Location \\
\hline Mdc1 & 0 & N/A \\
\hline Mdc2 & 2 & Cytosolic \\
\hline Mdc3 & 0 & N/A \\
\hline Mdc4 & 0 & N/A \\
\hline Mdc6 & 1 & Nuclear + Cytosolic \\
\hline Mdc7 & 0 & Nuclear + Cytosolic \\
\hline Mdc8 & 2 & N/A \\
\hline Mdc9 & 0 & Nuclear + Cytosolic \\
\hline Mdc10
\end{tabular}

Table 8: This table show the expression patterns of moderately differentiated carcinoma.

The location refers to the intracellular location. Samples that have nuclear and cytosolic expression indicate that there cells are expressing either in the nucleus or the cytosol. 

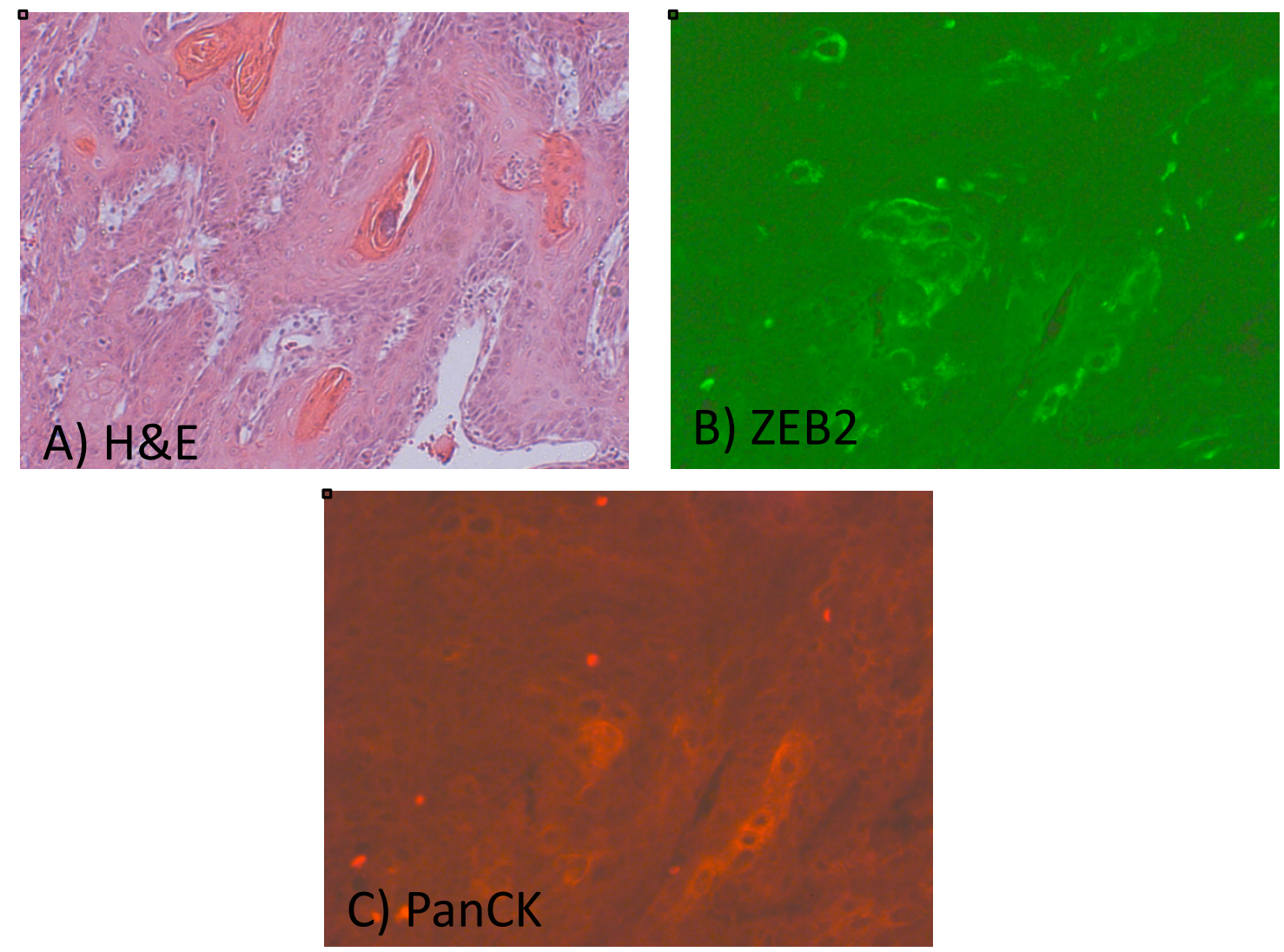

Figure 9: ZEB2 Expression in Moderately Differentiated Carcinoma. In moderately differentiated carcinoma there is a loss of organization as can be seen in the H\&E image. There was a decreased expression of ZEB2 throughout the samples, those that did stain positively did mostly in the cytosol as pictured above. 


\section{Poorly Differentiated Carcinoma}

The last stage of carcinoma, poorly differentiated carcinoma, is the most disorganized. In poorly differentiated carcinoma, ZEB2 expression in tumor cells occurs

either in the nucleus, the cytosol, or a mixture of cells expressing either in the nucleus or the cytosol. Concomitant nuclear and cytosolic expression of ZEB2 was the most frequent pattern observed. The proportion of cells expressing ZEB2 increased to well over $50 \%$, and the majority of these cells show nuclear ZEB2 expression. Hence, the transition to this grade includes a broad increase in nuclear ZEB2 expression. Cells of epithelial origin (as labelled by pan-cytokeratin) expressing ZEB2 tended to express cytokeratin in lower amounts than those that are not expressing ZEB2; this observation had been seen consistently throughout the different grades of carcinoma. ZEB2 expression is not only limited to cells of epithelial origin; it is also present in the cells of the surrounding stroma. The results for ZEB2 expression in poorly differentiated carcinoma are outlined in Table 9 and a representative sample is shown in Figure 10. 
Table 9: ZEB2 Expression Poorly Differentiated Carcinoma (PC)

\begin{tabular}{|c|c|c|}
\hline Sample & Strength & Location \\
\hline PC1 & 2 & Nuclear + Cytosolic \\
\hline PC2 & 2 & Nuclear + Cytosolic \\
\hline PC3 & 3 & Cytosolic \\
\hline PC4 & 0 & N/A \\
\hline PC5 & 3 & Nuclear + Cytosolic \\
\hline PC6 & 2 & Nutosolic \\
\hline PC7 & 2 & N/A \\
\hline PC8 & 0 & Nuclear + Cytosolic \\
\hline PC9 & 3 & N/A \\
\hline PC10 & 0 & carcinoma Z \\
\hline
\end{tabular}

Table 9: This table shows the data for poorly differentiated carcinoma ZEB2 staining

patterns. Nuclear and cytosolic indicate that cells were expressing ZEB2 in nucleus or in the cytosol. 

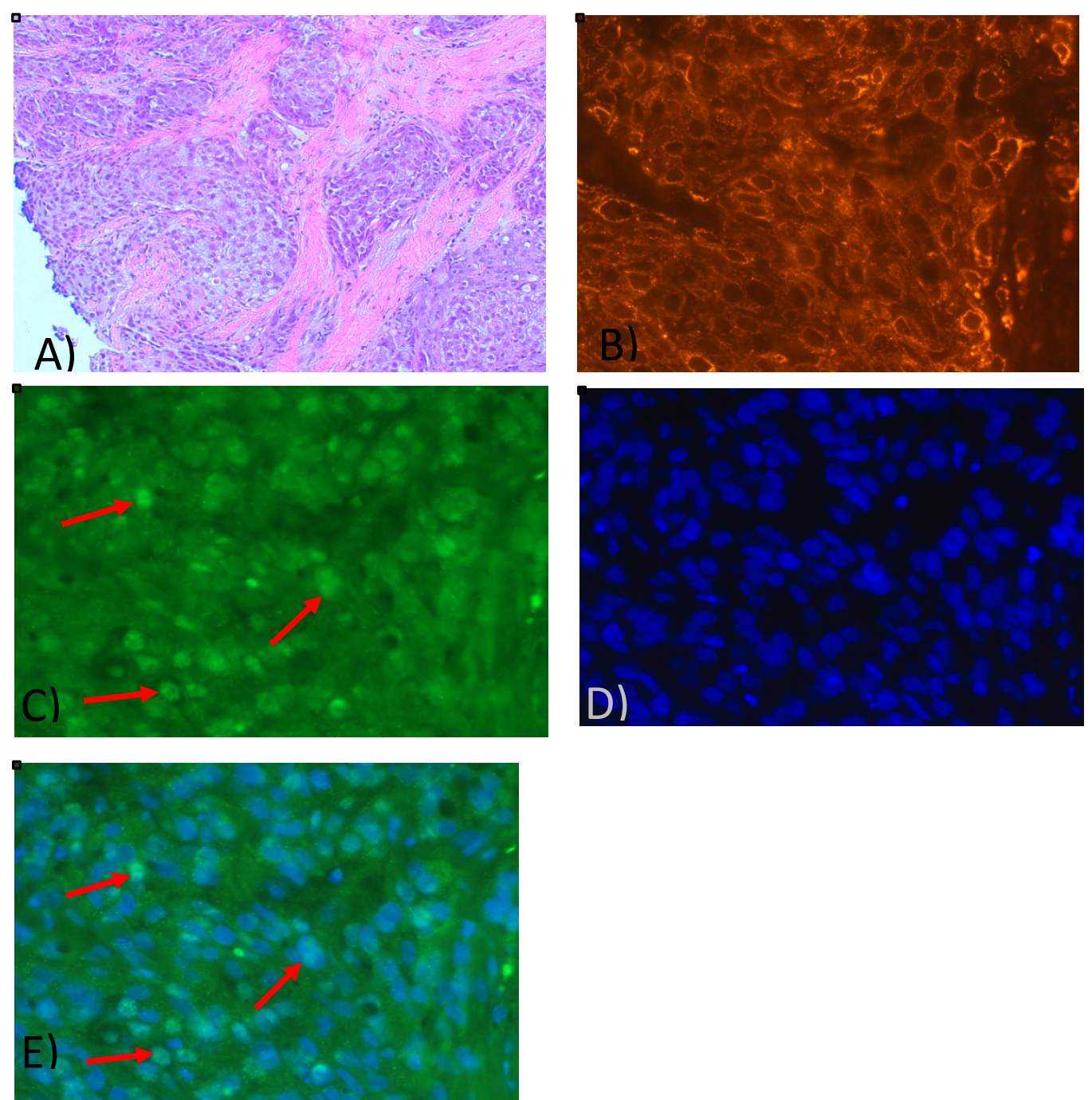

Figure 10: ZEB2 Expression in Poorly Differentiated Carcinoma. A) H\&E image at low power showing tissue disorganization. B) 40X image displaying epithelial cells with positive pan-cytokeratin. C) 40X ZEB2 (green) showing strong nuclear expression in all cells in this field. D) DAPI stain to confirm the location of the nuclei. E) DAPI and ZEB2 overlay confirming that there is both nuclear and cytosolic expression of ZEB2 in this sample. The red arrows point to the ZEB2 positive nuclei. 


\section{Statistical Analysis}

Using the Prism5 software from GraphPad, the ordinal data were analyzed using the Kruskal-Wallis test for non-parametric data (ANOVA), followed by Dunn's Multiple Comparison. The median of the ZEB2 intensity for each grade was analyzed by KruskalWallis to see if there were any differences across the data set as a whole. The KruskalWallis p-value was 0.0023 , indicating significant differences. This was followed by Dunn's Multiple Comparison to identify which individual groups differed. The results are summarized in Table 10 and Figure 11. Data show that the expression of ZEB2 is higher in CIS than in LDy $(\mathrm{p}<0.01)$ or in MDy $(\mathrm{p}<0.05)$. This is readily seen by comparing Figure 4A (LDy) and Figure 7A (CIS). 
Table 10: Summary of Dunn's Multiple Comparison Test for ZEB2

\begin{tabular}{|c|c|}
\hline Histological Grades Compared & $p$-value \\
\hline LDy vs. MDy & No \\
\hline LDy vs. SDy & Yes, $\mathrm{p}<0.01$ \\
\hline LDy vs. CIS & No \\
\hline MDy vs. SDy & Yes, $\mathrm{p}<0.05$ \\
\hline MDy vs. CIS & No \\
\hline SDy vs. CIS & \\
\hline
\end{tabular}

Table 10: This table compares the scores of the different histological grades with respect to their ZEB2 expression levels. The significance level assigned is $p<0.05$. Based on these results there is a statistically significant difference between mild dysplasia and carcinoma in situ as well as between moderate dysplasia and carcinoma in situ. 


\section{ZEB2 Expression Increases in CIS}

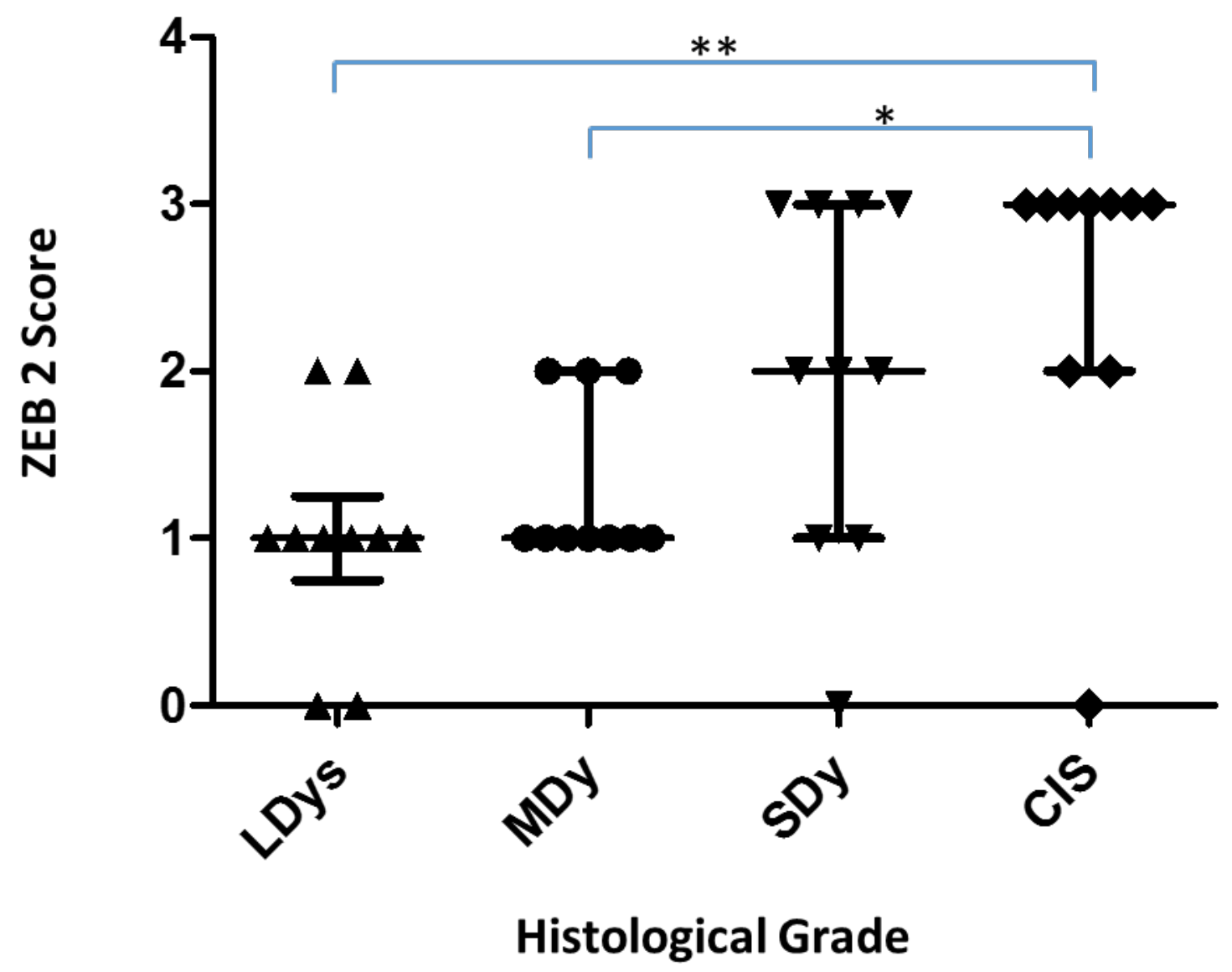

Figure 11: This graph shows the scores for ZEB2 in the different histological grades.

Data are the median and the interquartile range for $\mathrm{N}=10$ for each grade. Dunn's Multiple Comparison shows a significant increase of the median in the CIS group. * $\mathrm{p}<0.05, * * \mathrm{p}<0.01$ 


\section{ZEB1 Expression}

ZEB1 protein expression varied between healthy tissue, oral epithelial dysplasia, CIS, and the different grades of carcinoma. In histologically normal tissue nuclear ZEB1 expression was apparent primarily in the basal and spinous layers of the epithelium, with scattered cells with nuclear ZEB1 expression in upper regions of the epithelium. In all stages examined, approximately $20 \%$ to $30 \%$ of cells in the stroma show nuclear ZEB1 expression. In dysplasia, the expression of ZEB1 remained in and near the basal layer, and was primarily nuclear. In moderate and severe cases of dysplasia there was nuclear expression of ZEB1 near the basal layer in addition to a few cells with cytosolic expression in the spinous layer.

In samples diagnosed as carcinoma in situ, expression of ZEB1 was strongly expanded and observed throughout the thickness of the epithelium. The number of cells expressing ZEB1 increased as compared to dysplasia and the expression was predominantly nuclear. However, the level of expression of ZEB1 was weak to moderate in CIS samples. All CIS samples expressed ZEB1 and the staining patterns are outlined in Table 10.

ZEB1 expression in well differentiated carcinoma expression varied between the patients. In each sample, most of the expression of ZEB1 was located in and surrounding the characteristic keratin pearls. The samples varied in the number of cells expressing ZEB1 from $25 \%$ to over $75 \%$ of cells. ZEB1 expression was apparent in cells expressing pan-cytokeratin as well as a subset of cells in the surrounding stroma. The intensity of expression of ZEB1 was moderate to strong. In addition, in epithelium not associated 
with a keratin pearl, discrete areas of cytosolic ZEB1 expression were identified in cells adjacent to the stroma. This may indicate a change in signaling from the stroma.

In moderately differentiated carcinoma, the subcellular location of ZEB1 varied the most among one single grade. There were three different subsets that were apparent with equal frequency: nuclear, cytosolic, or both nuclear and cytosolic. Additionally, the proportion of cells expressing ZEB1 also varied among the different samples. Anywhere from $25 \%$ to over $75 \%$ of cells express ZEB1. Despite these differences all the samples displayed moderate expression of ZEB1.

Poorly differentiated carcinoma expressed ZEB1 either in the nucleus of certain cells, or in the cytosol of other cells. The proportion of tumor cells that expressed ZEB was also well over $50 \%$ of cells in all samples. The staining intensity for ZEB1 was weak to moderate. Of all the grades studied, the most abundant ZEB1 expression was observed in the most advanced carcinomas while early carcinoma expressed it in lower amounts; specifically, the proportion of cells expressing ZEB1 was higher in poorly differentiated carcinoma. There was a shift in ZEB1 expression from only nuclear in healthy tissue to a mixture of cells with nuclear or cytosolic in carcinoma. The patterns of expression of ZEB1 protein are summarized in Table 9 to show the proportion of biopsies with nuclear or cytosolic expression of ZEB1 for each of the different grades. This shows that the subcellular location of ZEB1 progresses from predominantly nuclear in dysplasia and CIS to heavily cytosolic in the most advanced stage of carcinoma. The expression patterns of ZEB1 are displayed in Figure 11. 
Table 11 ZEB1 Expression Summary

\begin{tabular}{|l|c|c|c|c|}
\hline \multicolumn{1}{|c|}{ Grade } & Negative & Nuclear & $\begin{array}{c}\text { Nuclear + } \\
\text { Cytosolic }\end{array}$ & Cytosolic \\
\hline Carcinoma In Situ & $0 / 10$ & $7 / 10$ & $3 / 10$ & $0 / 10$ \\
\hline $\begin{array}{l}\text { Well differentiated } \\
\text { Carcinoma }\end{array}$ & $1 / 10$ & $6 / 10$ & $1 / 10$ & $2 / 10$ \\
\hline $\begin{array}{l}\text { Moderately Differentiated } \\
\text { Carcinoma }\end{array}$ & $0 / 9$ & $3 / 9$ & $3 / 9$ & $3 / 9$ \\
\hline $\begin{array}{l}\text { Poorly Differentiated } \\
\text { Carcinoma }\end{array}$ & $0 / 9$ & $4 / 10$ & $1 / 10$ & $5 / 10$ \\
\hline
\end{tabular}

Table 11: This table shows all the data for ZEB1 expression in carcinoma in situ, well differentiated carcinoma, moderately differentiated carcinoma, and poorly differentiated carcinoma. 

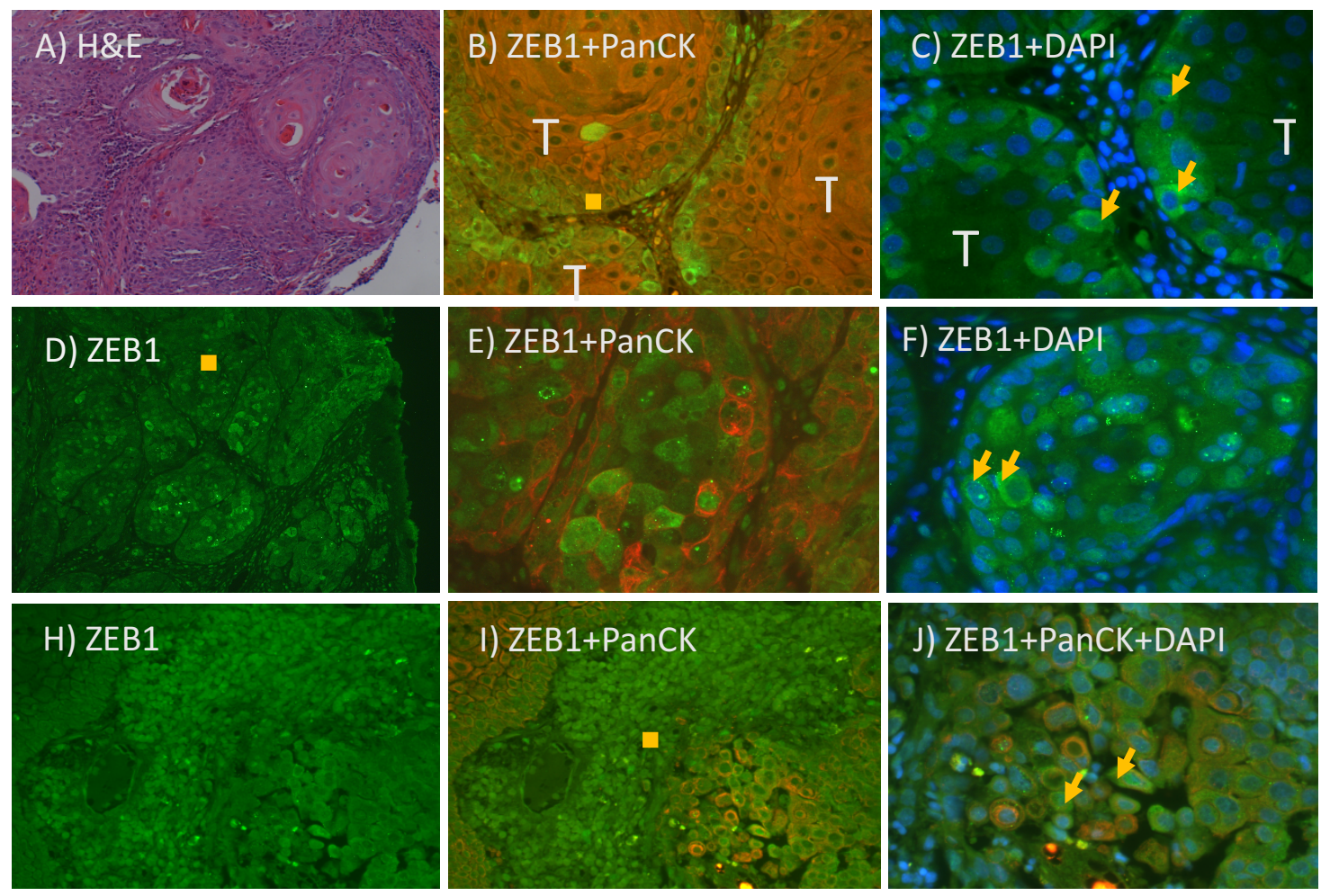

Figure 12: ZEB1 Expression. A) Low power well-differentiated carcinoma showing characteristic keratin pearls B) 20X Pan-cytokeratin indicating cells of epithelial origin, ZEB1 is expressed in the cytosol of the cells that are on the periphery of the tumor islands (indicated by T) C) High power DAPI merge with ZEB1 expression in the cytosol, indicated by the yellow arrows D) ZEB1 expression in moderately differentiated carcinoma, the expression is spread throughout the cancer sample E) Higher power image of ZEB1 and Pan-cytokeratin confirming tumor cells F) DAPI and ZEB1 merge indicating the cytosolic expression of ZEB1, indicated by the yellow arrows H) Poorly differentiated carcinoma with abundant nuclear ZEB1 expression in the stroma and minimal cytosolic expression in the tumor cells I) Pan-cytokeratin identifying tumor cells with ZEB1 expression in both the tumor cells and adjacent stroma J) ZEB1 expression in tumor cells in the cytosol of tumor cells (yellow arrows). 
Figure 13: ZEB1 and ZEB2 Comparison
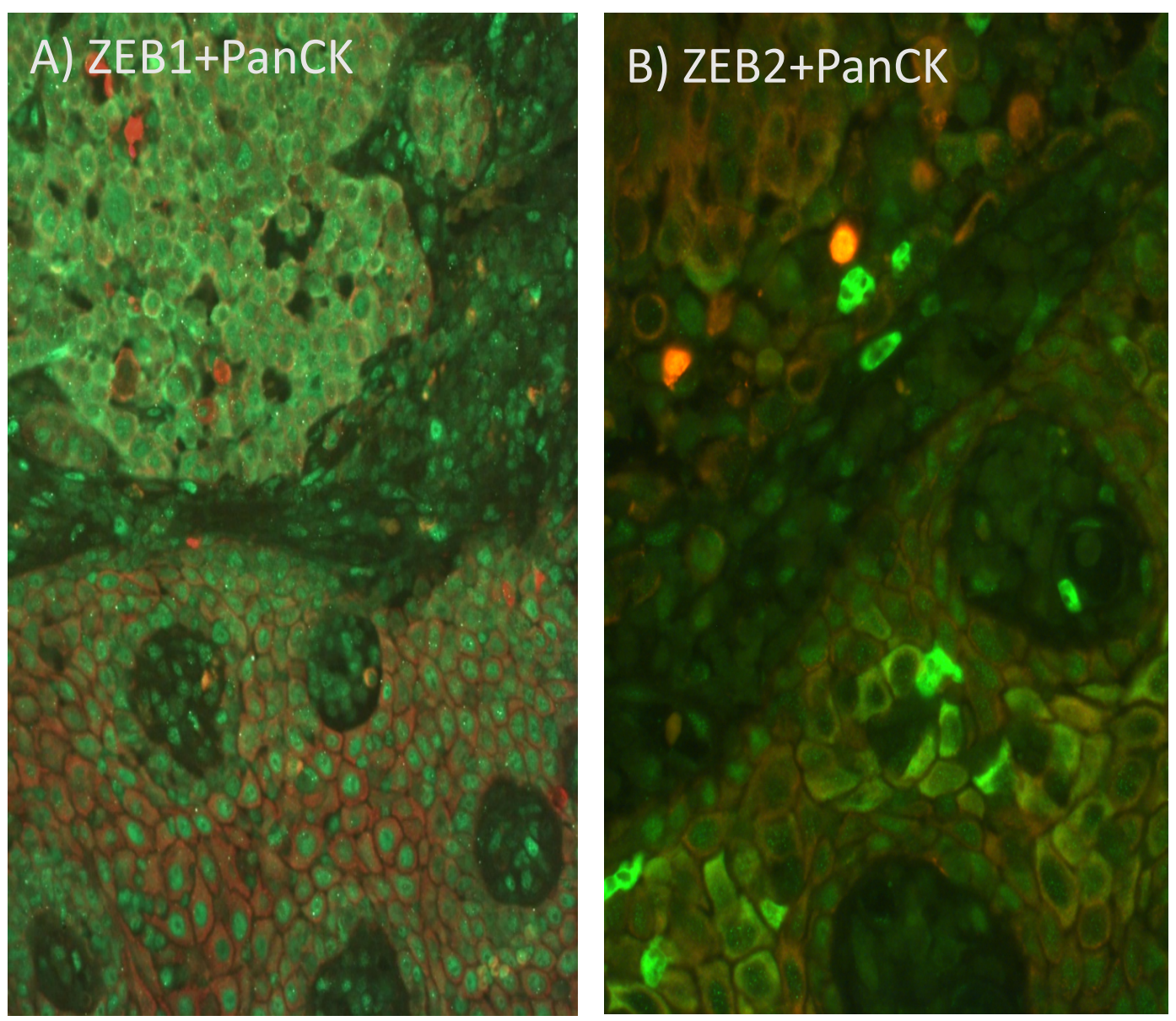

Figure 13: A) In this sample of poorly differentiated carcinoma the epithelial tissue adjacent to the tumor shows ZEB1 nuclear expression and cytosolic expression of ZEB1 in the tumor itself. B) The ZEB2 expresion in the epithelial tissue is cytosolic while in the tumor cells there is very low expression of ZEB2. 


\section{CHAPTER IV}

\section{DISCUSSION}

_ZEB1 and ZEB2 have distinct roles and different expression patterns during embryonic development. They are expressed in non-overlapping tissue domains in most regions, but are co-expressed in neural crest cells and the ventricular zone of the developing brain (Miyoshi, Maruhashi et al. 2006). ZEB1 has broad developmental effects, influencing immune cell differentiation, skeletal patterning, immune differentiation, palate formation, and neural crest development (Gheldof, Hulpiau et al. 2012). Homozygous ZEB1 knockout mice survive through embryogenesis, being viable until shortly after birth. In humans, heterozygous ZEB1 mutation leads to posterior polymorphous corneal dystrophy, involving metaplasia and overgrowth of corneal endothelial cells (Liskova, Tuft et al. 2007). In contrast, ZEB2 knockout mice do not live past embryonic day 8.5 (Miyoshi, Maruhashi et al. 2006); and in humans, a heterozygous mutation in ZEB2 results in Mowat-Wilson syndrome which is characterized by mental retardation, microcephaly, short stature and a distinctive facial appearance (Fang, Zeng et al. 2014). Despite their distinct developmental roles, they apparently have similar molecular roles in cancer. Both ZEB1 and ZEB2 are associated with cancer progression and metastasis, especially the process of EMT (Vandewalle, Van Roy et al. 2009). ZEBs cause EMT by direct regulation of E-cadherin, vimentin, and other effector genes (Lamouille, Xu et al. 2014). In addition, each ZEB contributes to cancer stem cell 
generation by inhibiting key microRNAs (Wellner, Schubert et al. 2009) (Polytarchou, Iliopoulos et al. 2012). Enhancement of the EMT-associated stemness phenotype by ZEB1 or ZEB2 also causes increased drug- and radio-resistance of tumors (Siebzehnrubl, Silver et al. 2013) (Sayan, Griffiths et al. 2009) (Fang, Zeng et al. 2014), and disruption of the ZEB1/miR203 pathway is being investigated as a therapeutic approach to re-sensitize tumors (Meidhof, Brabletz et al. 2015). These molecular effects are likely the basis for the observations that ZEB1 or ZEB2 is strongly expressed at the aggressive front of tumors and their expression correlates with a poorer prognosis for several cancers (Brabletz and Brabletz 2010, Fang, Zeng et al. 2014). However, the role of ZEBs in oral squamous cell carcinoma has been less studied than other cancers (Chen, Zimmermann et al. 2013). ZEB1 and ZEB2 mRNA levels have been linked with poorer prognosis in head and neck cancer (Chu, Hu et al. 2013), however, protein expression and comparison of these two genes at the protein level was not examined. ZEB expression has been related to tumor initiation of several cancers such as lung, pancreatic, and also including OSCC (Chu, Hu et al. 2013). Therefore, we examined the expression and subcellular location of ZEB1 and ZEB2 during the early grades leading to oral squamous cell carcinoma with the aim of evaluating its utility as a biomarker.

In this study, ZEB1 protein expression varied between healthy tissue, oral epithelial dysplasia, CIS, and the different grades of carcinoma. In histologically normal epithelium, ZEB1 expression was apparent primarily in nuclei of basal and spinous layers of the epithelium, with scattered cells having nuclear ZEB1 expression in upper regions 
of the epithelium. This pattern suggests that ZEB1 expression decreases or is lost in most of the cells as they progress through differentiation into a keratinized epithelial cells. This is consistent with ZEB1 often being associated with more undifferentiated progenitor-like cells. This has been demonstrated with ZEB1 knockdown in cancer cells displaying a more epithelial, differentiated phenotype (Brabletz, Bajdak et al. 2011). In dysplasia the expression of ZEB1 remained in and near the basal layer, and was primarily nuclear. In moderate and severe cases of dysplasia there was nuclear expression of ZEB1 near the basal layer in addition to some cytosolic expression in the spinous layer. In samples diagnosed as carcinoma in situ, expression of ZEB1 was observed throughout the thickness of the epithelium. The number of cells expressing ZEB1 clearly increased as compared to dysplasia, however the expression remained predominantly nuclear. The level of expression of ZEB1 was weak to moderate in CIS samples. The broad expression of ZEB1 observed in CIS, along with histological appearance, may render ZEB1 a useful marker for CIS. In addition to the epithelial cells there was also ZEB1 nuclear expression seen in the surrounding stromal cells. These cells did not stain positively for pan-cytokeratin therefore indicating they are not epithelial cells. These cells are components of the underlying connective tissue, but which types of cells has not been ascertained. Since similar cells are observed in histologically normal tissue, these ZEB1+ cells may reflect normal expression of ZEB1 in immune cells and/or a subset of fibroblasts. The presence of ZEB1 in these stromal cells may indicate some role 
influencing the tumor microenvironment, however clear changes in stromal ZEB1 expression were not observed in different grades of cancer.

ZEB1 expression in well differentiated carcinoma varied between the patients. In each sample, most of the expression of ZEB1 was located in and surrounding the characteristic keratin pearls. The samples varied in the number of cells expressing ZEB1 from $25 \%$ to over $75 \%$ of cells. ZEB1 expression was apparent in cells expressing pancytokeratin as well as a subset of cells in the surrounding stroma. The intensity of expression of ZEB1 was moderate to strong. In addition, in epithelium not associated with a keratin pearl, discrete areas of cytosolic ZEB1 expression were identified in cells adjacent to the stroma. This may indicate a change in signaling from the stroma. In addition, it would be of interest to investigate whether the different frequency of ZEB1 expression in patients correlates with different clinical outcomes.

In moderately differentiated carcinoma, the subcellular location of ZEB1 varied the most among one single grade. There were three different subsets that were observed with equal frequency: nuclear, cytosolic, or both nuclear and cytosolic. The nuclear and cytosolic expression pattern means that some cells were expressing both in the nucleus and cytosol or it was nuclear in some cells and cytosolic in others. Additionally, the proportion of cells expressing ZEB1 also varied among the different samples. Anywhere from $25 \%$ to over $75 \%$ of cells express ZEB1. Despite these differences all the samples displayed moderate expression of ZEB1. Overall, there was a marked increase in the expression of ZEB1 in moderately differentiated carcinoma.

Poorly differentiated carcinoma samples expressed ZEB1 either in the nucleus of certain cells, or in the cytosol of other cells. The proportion of tumor cells that expressed 
ZEB was well over $50 \%$ of cells in all samples. The staining intensity for ZEB1 was weak to moderate. Of all the carcinoma grades studied, the most abundant ZEB1 expression was observed in the most advanced carcinomas while early carcinoma expressed it in lower amounts. There was a shift in ZEB1 expression from only nuclear in healthy tissue to a mixture of cells with nuclear or cytosolic in carcinoma. The subcellular location of ZEB1 progresses from predominantly nuclear in dysplasia and CIS to heavily cytosolic in the most advanced stage of carcinoma. Importantly, this is the first demonstration of a shift from nuclear to cytosolic ZEB1 in different grades of cancer. Phosphorylation of ZEB1 by specific kinase pathways has been shown experimentally to cause cytosolic localization (Llorens, Lorenzatti et al. 2016), however, this is the first demonstration of a change in localization in vivo. ZEB1 in the cytosol is not able to regulate transcription of target genes, and would be expected to reduce the EMT-characteristics of these cells. This change of signaling may be occurring due to changes in the surrounding environment of the cancer cells. Samples graded as well differentiated carcinoma frequently contained areas where groups of basal epithelial cells adjacent to the stroma displayed cytosolic ZEB1, suggesting a change in stromal signaling. In the more advanced cancers, the about half the cells were expressing ZEB1 in the cytosol while the other half showed expression in the nucleus. This would be worthwhile to examine clinical outcomes to see how this pattern may be associated.

ZEB2 is closely related, but distinctly different from ZEB1 and therefore it is worthwhile looking at expression of ZEB2 in addition to ZEB1. It is also worthwhile to compare the two. Changes of ZEB2 protein expression were also observed between the different pathological grades. These changes were especially evident in comparing 
dysplasia and carcinoma in situ and also between moderately differentiated carcinoma and poorly differentiated carcinoma. Generally, histologically healthy tissue expressed nuclear ZEB2 moderately in the basal layer; however, in the suprabasal layer scattered cells express ZEB2 in the cytosol. Approximately $25-50 \%$ of the cells express ZEB2 in the epithelium.

In oral epithelial dysplasia, nuclear ZEB2 expression occurred most frequently in the basal layer with a clear band of cytosolic expression in the suprabasal cells; this pattern appeared consistently throughout the three grades of dysplasia (mild, moderate, severe). Based on statistical analysis, there were significant differences in the medians of the following categories: mild dysplasia and CIS and moderate dysplasia and CIS. These results suggests that the differences between these subsets are more apparent than the other categories. The results are summarized in Table 10.

In samples of CIS, ZEB2 stained overwhelmingly in either the nucleus or the cytosol with $70 \%$ of the samples staining with the pattern in Figure 7. ZEB2 positive samples stained in a ubiquitous manner with the staining occurring throughout the thickness of the epithelium and not restricted to specific areas as observed in dysplasia. Nonetheless, many more cells in the spinous layer showed strong cytosolic expression of ZEB2 protein. This is a clear expansion of mid-epithelial cytosolic expression as compared to dysplasia samples. This change in expression may indicate that the cells are undergoing phenotypic changes. Based on the statistical analysis summarized in Table 10 , it was determined that there is a statistically significant difference in expression of ZEB2 between mild dysplasia and CIS as well as between moderate dysplasia and CIS. 
As compared to CIS, there are pronounced changes in ZEB2 expression in well differentiated carcinoma. First of all, ZEB2 was predominantly expressed in the cytosol with few instances of nuclear expression. The number of cells expressing ZEB2 was also decreased. Furthermore, the expression of ZEB2 was weak to moderate. Cytosolic ZEB2 expression was mostly seen in cells at the edges of the keratin pearls.

In moderately differentiated carcinoma, cells continued to express ZEB2 in the cytosol, but fewer than $25 \%$ of the cells were expressing ZEB2. The subcellular location remained the same, but there was a decrease in the number of cells expressing ZEB2. In this grade there was almost exclusively cytosolic expression. Cells expressing ZEB2 did so weakly or moderately at best. As was observed in well-differentiated carcinoma, cells that were expressing ZEB2 were located on the periphery of the keratin pearls. (Figure 8).

In poorly differentiated carcinoma, ZEB2 expression in tumor cells occurs either in the nucleus, the cytosol, or a mixture of cells expressing either in the nucleus or the cytosol. Concomitant nuclear and cytosolic expression of ZEB2 was the most prominent pattern observed. The proportion of cells expressing ZEB2 increased to well over 50\%. Cells of epithelial origin (as labelled by pan-cytokeratin) expressing ZEB2 tended to express cytokeratin in lower amounts than those that are not expressing ZEB2; this observation had been seen consistently throughout the different grades of carcinoma. ZEB2 expression is not only limited to cells of epithelial origin; it is also present in the cells of the surrounding stroma.

Despite ZEB1 and ZEB2 having overlapping molecular activities their expression patterns were distinct throughout oral epithelial dysplasia, CIS, and the different grades 
of squamous cell carcinoma. In normal tissue, ZEB1 expression occurred only in the nucleus, primarily in the basal cell layers, whereas ZEB2 was largely restricted to cytosolic expression in the suprabasal layer. For ZEB1, mildly dysplastic tissue also has predominantly nuclear expression with some cytosolic expression evident in more moderate and severe dysplasia. The staining pattern for ZEB2 in all types of dysplasia was similar to normal tissue, some nuclear expression in the basal layer with cytosolic in the spinous layer. For CIS, ZEB1 expression was mainly nuclear throughout the epithelium. Conversely, ZEB2 expression was found in the nucleus of some cells, but was widely expressed in the cytosol of cells throughout the mid-epithelium. As the carcinoma loses differentiation into moderately differentiated carcinoma ZEB1 continued to be expressed in the nucleus or the cytosol whereas ZEB2 was mainly expressed in the cytosol. In the most poorly differentiated cases ZEB2, rather than ZEB1, is predominantly expressed in the nucleus. There does not appear to be any association between the expression of ZEB1 and ZEB2 in poorly differentiated carcinoma with regards to subcellular location, strength, or distribution.

During normal development in the mouse, both ZEB1 and ZEB2 are consistently nuclear (Darling, Stearman et al. 2003, Van de Putte, Francis et al. 2007). Our data show that in histologically normal tongue epithelium and during dysplasia ZEB1 is consistently expressed in the nucleus of the basal and spinous layers of the epithelium, with sporadic expression in cells in higher levels. In carcinoma in situ the expression of ZEB1 protein expands to additional cells throughout the epithelium, and in many samples is present throughout the cell. Well differentiated carcinoma is characterized by keratin pearls; these structures are pan-cytokeratin positive and are surrounded by connective tissue 
(Woolgar and Triantafyllou 2011). In this grade of carcinoma, ZEB1 continues to be expressed in the nucleus of cells in and around the keratin pearls. However, in two of the 10 well differentiated carcinomas the ZEB1 expression was strongly cytosolic and limited to cells at the edge of the pearls, adjacent to the stroma. Localized areas of epithelium adjacent to the stroma also show strong cytosolic expression, suggestive of signaling from the stroma. This appears to begin a progression of increasingly cytosolic localization of ZEB1 protein as the cancer progresses. In poorly differentiated carcinoma, all tumors express ZEB1, with about half the biopsies showing only nuclear ZEB1 protein, and half the biopsies having primarily cytosolic ZEB1. These two subsets of nuclear versus cytosolic localization of ZEB1 raise the possibility of different roles of this protein in different patients. Table 12 demonstrates differences in expression of ZEB1 and ZEB2 in poorly differentiated carcinoma.

ZEB2 is nuclear during development (Van de Putte, Francis et al. 2007). ZEB2 in tongue epithelium is expressed in the nucleus of the basal layer of cells; however we also observed a thin band of occasional scattered cells in the suprabasal layer having only cytosolic expression of ZEB2. In samples graded as carcinoma in situ, the strong cytosolic expression of ZEB2 protein is greatly expanded to a large proportion of cells across the middle of the epithelium. In well differentiated cancer fewer cells expressed ZEB2 and these were restricted to areas adjacent to or between the keratin pearls. In moderately differentiated oral cancer ZEB2 continued to be largely cytosolic. However, in poorly differentiated cancers ZEB2 was commonly expressed in the nucleus of cells. Most of these biopsies shows a mixture of cells expressing either nuclear or cytosolic ZEB2. 
While ZEB1 has never previously been characterized as being cytosolic, there are some instances of ZEB2 in the cytosol (Oztas, Avci et al. 2010, Yang, Sun et al. 2015). In a tissue array of advanced cancers, ZEB2/SIP1 was overexpressed in the cytosol of cancers of the kidney, breast, lung and uterus (Oztas, Avci et al. 2010). Importantly, in colon cancer and cholangiocarcinoma ZEB2 was almost exclusively cytosolic and yet expression correlated with tumor stage and patient survival (Kahlert, Lahes et al. 2011), or metastasis (Techasen, Loilome et al. 2014). These results are consistent with our observation of cytosolic ZEB2 in OSCC, and importantly indicate that even in the cytosol ZEB2 may have clinically significant effects. Nonetheless, in the most severe grade of OSCC we typically observed a mix of cells with cytosolic or nuclear ZEB2.

The presence of ZEB1 and ZEB2 in the cytosol of specific cells implies a molecular mechanism for regulating the subcellular distribution of ZEBs. Two functionally related EMT-TFs, Snail and Twist, are regulated in part by phosphorylation which directly shifts nuclear localization (Lamouille, Xu et al. 2014). Unlike ZEB2, high expression of Snail1 in the nucleus, but not cytosol, is significantly related to a worse patient survival in nasopharyngeal carcinoma (Luo, Fang et al. 2012) (Sánchez-Tilló, Liu et al. 2012). We have identified nuclear localization signal sequences in ZEB1 and find that phosphorylation of adjacent $\mathrm{S} / \mathrm{T}$ sites can regulate subcellular localization and function (Llorens, Lorenzatti et al. 2016). Whatever the mechanism, exclusion from the nucleus may be a means to repress transcriptional regulation by ZEBs. In addition, ZEBs may have unknown molecular functions in the cytosol.

The TGF- $\beta$ pathway is a part of EMT during wound-healing (Lamouille, $\mathrm{Xu}$ et al. 2014). It is also been well established that TGF- $\beta$ protein and mRNA levels are 
elevated in many different cancers such as breast, lung, prostrate, and stomach cancers (Gold 1998). By repressing E-cadherin and initiating EMT, both ZEB1 and ZEB2 have been shown to enhance the effects of TGF- $\beta$ (Peinado, Olmeda et al. 2007). In a study using Madine-Darby canine kidney cells, it has been demonstrated that exogenously elevated levels of TGF- $\beta$ increase the level of expression of both ZEB1 and ZEB2; the implication of this being that TGF- $\beta$ is promoting an mesenchymal phenotype and that phenotype is maintained by elevated levels of ZEB1 and ZEB2 (Gregory, Bracken et al. 2011). Additionally, when ZEB1 and ZEB2 levels were decreased by using siRNA, miR$200 \mathrm{a}$, or miR-200b the cells were able to revert back to an epithelial phenotype. Though both ZEB1 and ZEB2 are part of the TGF- $\beta$ pathway via Smad interaction, they both act in different ways; ZEB1 activates transcription while ZEB2 inhibits transcription (Postigo 2003). The differences in expression patterns that were detected in this study may be explained by this observation; there are different expression patterns for both ZEB1 and ZEB2 in the various stages of carcinoma. Overall, they are both helping to maintain a mesenchymal phenotype, but they each regulate gene expression in different ways. 


\section{Major Observations}

1. ZEB1 is nuclear in the normal basal cell layer, and can be shifted to cytosolic localization in later pathological grades in oral cancer.

2. The proportion of cells expressing ZEB1 increases with increasing pathological grade in OSCC. In poorly differentiated carcinoma, all tumors express ZEB1, with about half the biopsies showing only nuclear ZEB1 protein, and half the biopsies having primarily cytosolic ZEB1.

3. Histologically healthy tissue expressed nuclear ZEB2 in the basal layer; however, in the suprabasal layer some cells express ZEB2 in the cytosol.

4. In carcinoma in situ, the strong cytosolic expression of ZEB2 protein is greatly expanded to a large proportion of cells across the middle of the epithelium. 


\section{Future Directions}

The data gathered in this study reveals that there are many different possibilities to explore regarding the transcription factors ZEB1 and ZEB2. EMT is an interesting aspect of cancer biology that should be further explored. One of the limitations of this study was the fact that patient survival data, HPV, and smoking status were unknown. It would be beneficial to acquire other data sets that would allow the opportunity to explore this information and to see if correlations exist between ZEB expression and localization with the aforementioned clinical parameters. Furthermore, it would be interesting to see what the expression of ZEB factors would be in regional lymph nodes in cases of metastatic disease also. 


\section{REFERENCES}

1. American Cancer Society. Cancer facts \& figures. Atlanta, GA, The Society: v. Andrews, E., W. T. Seaman and J. Webster-Cyriaque (2009). "Oropharyngeal carcinoma in non-smokers and non-drinkers: A role for HPV." Oral Oncology 45(6): 486-491.

Bauer, M., G. Su, C. Casper, R. He, W. Rehrauer and A. Friedl (2010). "Heterogeneity of gene expression in stromal fibroblasts of human breast carcinomas and normal breast." Oncogene 29(12): 1732-1740.

Bello, I. O., M. Vered, D. Dayan, A. Dobriyan, R. Yahalom, K. Alanen, P. Nieminen, S. Kantola, E. Läärä and T. Salo (2011). "Cancer-associated fibroblasts, a parameter of the tumor microenvironment, overcomes carcinoma-associated parameters in the prognosis of patients with mobile tongue cancer." Oral oncology 47(1): 33-38.

Brabletz, S., K. Bajdak, S. Meidhof, U. Burk, G. Niedermann, E. Firat, U. Wellner, A. Dimmler, G. Faller and J. Schubert (2011). "The ZEB1/miR- 200 feedback loop controls Notch signalling in cancer cells." The EMBO journal 30(4): 770-782.

Brabletz, S. and T. Brabletz (2010). "The ZEB/miR- 200 feedback loop-a motor of cellular plasticity in development and cancer?" EMBO reports 11(9): 670-677.

Bracken, C. P., P. A. Gregory, N. Kolesnikoff, A. G. Bert, J. Wang, M. F. Shannon and G. J. Goodall (2008). "A double-negative feedback loop between ZEB1-SIP1 and the 
microRNA-200 family regulates epithelial-mesenchymal transition." Cancer Res 68(19): 7846-7854.

Bradley, K. T., S. D. Budnick and S. Logani (2006). "Immunohistochemical detection of p16INK4a in dysplastic lesions of the oral cavity." Mod Pathol 19(10): 1310-1316. Brennan, M., C. A. Migliorati, P. B. Lockhart, D. Wray, I. Al-Hashimi, T. Axéll, A. J. Bruce, W. Carpenter, E. Eisenberg, J. B. Epstein, P. Holmstrup, M. Jontell, R. Nair, H. Sasser, M. Schifter, B. Silverman, K. Thongprasom, M. Thornhill, S. Warnakulasuriya and I. van der Waal (2007). "Management of oral epithelial dysplasia: a review." $\underline{\text { Oral }}$ Surgery, Oral Medicine, Oral Pathology, Oral Radiology, and Endodontology 103, Supplement(0): S19.e11-S19.e12.

Bronsert, P., I. Kohler, S. Timme, S. Kiefer, M. Werner, O. Schilling, Y. Vashist, F. Makowiec, T. Brabletz, U. T. Hopt, D. Bausch, B. Kulemann, T. Keck and U. F. Wellner (2014). "Prognostic significance of Zinc finger E-box binding homeobox 1 (ZEB1) expression in cancer cells and cancer-associated fibroblasts in pancreatic head cancer." Surgery 156(1): 97-108.

Chaturvedi, A. K., W. F. Anderson, J. Lortet-Tieulent, M. P. Curado, J. Ferlay, S. Franceschi, P. S. Rosenberg, F. Bray and M. L. Gillison (2013). "Worldwide trends in incidence rates for oral cavity and oropharyngeal cancers." Journal of Clinical Oncology 31(36): 4550-4559.

Chen, C., M. Zimmermann, I. Tinhofer, A. M. Kaufmann and A. E. Albers (2013). "Epithelial-to-mesenchymal transition and cancer stem(-like) cells in head and neck squamous cell carcinoma." Cancer Letters 338(1): 47-56. 
Chu, P.-Y., F.-W. Hu, C.-C. Yu, L.-L. Tsai, C.-H. Yu, B.-C. Wu, Y.-W. Chen, P.-I. Huang and W.-L. Lo (2013). "Epithelial-mesenchymal transition transcription factor ZEB1/ZEB2 co-expression predicts poor prognosis and maintains tumor-initiating properties in head and neck cancer." Oral Oncology 49(1): 34-41.

Comijn, J., G. Berx, P. Vermassen, K. Verschueren, L. van Grunsven, E. Bruyneel, M. Mareel, D. Huylebroeck and F. van Roy "The Two-Handed E Box Binding Zinc Finger Protein SIP1 Downregulates E-Cadherin and Induces Invasion." Molecular Cell 7(6): $1267-1278$.

Darling, D. S., R. P. Stearman, Y. Qi, M.-S. Qiu and J. P. Feller (2003). "Expression of

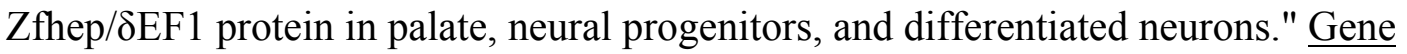
expression patterns $3(6)$ : 709-717.

Fang, S., X. Zeng, W. Zhu, R. Tang, Y. Chao and L. Guo (2014). "Zinc finger E-boxbinding homeobox 2 (ZEB2) regulated by miR-200b contributes to multi-drug resistance of small cell lung cancer." Experimental and Molecular Pathology 96(3): 438-444. Furusawa, T., H. Moribe, H. Kondoh and Y. Higashi (1999). "Identification of CtBP1 and CtBP2 as corepressors of zinc finger-homeodomain factor $\delta \mathrm{EF} 1 . "$ Molecular and cellular biology 19(12): 8581-8590.

Gheldof, A., P. Hulpiau, F. van Roy, B. De Craene and G. Berx (2012). "Evolutionary functional analysis and molecular regulation of the ZEB transcription factors." $\underline{\text { Cell Mol }}$ Life Sci 69(15): 2527-2541.

Ghoumid, J., L. Drevillon, S. M. Alavi-Naini, N. Bondurand, M. Rio, A. Briand-Suleau, M. Nasser, L. Goodwin, P. Raymond and C. Yanicostas (2013). "ZEB2 zinc-finger 
missense mutations lead to hypomorphic alleles and a mild Mowat-Wilson syndrome." Human molecular genetics: ddt114.

Gold, L. I. (1998). "The role for transforming growth factor-beta (TGF-beta) in human cancer." Critical reviews in oncogenesis 10(4): 303-360.

Grabitz, A. L. and M. K. Duncan (2012). "Focus on molecules: Smad Interacting Protein 1 (Sip1, ZEB2, ZFHX1B)." Exp Eye Res 101: 105-106.

Gregory, P. A., A. G. Bert, E. L. Paterson, S. C. Barry, A. Tsykin, G. Farshid, M. A. Vadas, Y. Khew-Goodall and G. J. Goodall (2008). "The miR-200 family and miR-205 regulate epithelial to mesenchymal transition by targeting ZEB1 and SIP1." Nature cell biology 10(5): 593-601.

Gregory, P. A., C. P. Bracken, E. Smith, A. G. Bert, J. A. Wright, S. Roslan, M. Morris, L. Wyatt, G. Farshid and Y.-Y. Lim (2011). "An autocrine TGF- $\beta / Z E B / m i R-200$ signaling network regulates establishment and maintenance of epithelial-mesenchymal transition." Molecular biology of the cell 22(10): 1686-1698.

Hanahan, D. and R. A. Weinberg (2000). "The hallmarks of cancer." Cell 100(1): 57-70. Higashi, Y., H. Moribe, T. Takagi, R. Sekido, K. Kawakami, H. Kikutani and H. Kondoh (1997). "Impairment of T cell development in deltaEF1 mutant mice." J Exp Med 185(8): 1467-1479.

Joyce, J. A. and D. T. Fearon (2015). "T cell exclusion, immune privilege, and the tumor microenvironment." Science 348(6230): 74-80.

Kahlert, C., S. Lahes, P. Radhakrishnan, S. Dutta, C. Mogler, E. Herpel, K. Brand, G. Steinert, M. Schneider and M. Mollenhauer (2011). "Overexpression of ZEB2 at the 
invasion front of colorectal cancer is an independent prognostic marker and regulates tumor invasion in vitro." Clinical Cancer Research 17(24): 7654-7663.

Kalluri, R. and E. G. Neilson (2003). "Epithelial-mesenchymal transition and its implications for fibrosis." The Journal of Clinical Investigation 112(12): 1776-1784. Kerosuo, L. and M. Bronner-Fraser (2012). What is bad in cancer is good in the embryo: importance of EMT in neural crest development. Seminars in cell \& developmental biology, Elsevier.

Kierszenbaum, A. L. and L. Tres (2015). Histology and cell biology: an introduction to pathology, Elsevier Health Sciences.

Korpal, M., E. S. Lee, G. Hu and Y. Kang (2008). "The miR-200 family inhibits epithelial-mesenchymal transition and cancer cell migration by direct targeting of Ecadherin transcriptional repressors ZEB1 and ZEB2." Journal of Biological Chemistry 283(22): 14910-14914.

Kumar, V., A. K. Abbas, J. C. Aster and S. L. Robbins (2013). Robbins basic pathology. Philadelphia, PA, Elsevier/Saunders.

Lamouille, S., J. Xu and R. Derynck (2014). "Molecular mechanisms of epithelialmesenchymal transition." Nat Rev Mol Cell Biol 15(3): 178-196.

Lechner, J., D. P. Dash, D. Muszynska, M. Hosseini, F. Segev, S. George, D. G. Frazer, J. E. Moore, S. B. Kaye and T. Young (2013). "Mutational Spectrum of the ZEB1 Gene in Corneal Dystrophies Supports a Genotype-Phenotype Correlation ZEB1 Gene in Corneal Dystrophies." Investigative ophthalmology \& visual science 54(5): 3215-3223. Lingen, M. W., J. R. Kalmar, T. Karrison and P. M. Speight "Critical evaluation of diagnostic aids for the detection of oral cancer." Oral Oncology 44(1): 10-22. 
Liskova, P., S. J. Tuft, R. Gwilliam, N. D. Ebenezer, K. Jirsova, Q. Prescott, R. Martincova, M. Pretorius, N. Sinclair and D. L. Boase (2007). "Novel mutations in the ZEB1 gene identified in Czech and British patients with posterior polymorphous corneal dystrophy." Human mutation 28(6): 638-638.

Liu, Y., S. El-Naggar, D. S. Darling, Y. Higashi and D. C. Dean (2008). "Zeb1 links epithelial-mesenchymal transition and cellular senescence." Development 135(3): 579588.

Liu, Y., X. Peng, J. Tan, D. S. Darling, H. J. Kaplan and D. C. Dean (2008). "Zeb1 mutant mice as a model of posterior corneal dystrophy." Investigative ophthalmology \& visual science 49(5): 1843-1849.

Liu, Y., E. Sanchez-Tillo, X. Lu, L. Huang, B. Clem, S. Telang, A. B. Jenson, M. Cuatrecasas, J. Chesney, A. Postigo and D. C. Dean (2014). "The ZEB1 transcription factor acts in a negative feedback loop with miR200 downstream of Ras and Rb1 to regulate Bmil expression." J Biol Chem 289(7): 4116-4125.

Llorens, M. C., G. Lorenzatti, N. L. Cavallo, M. V. Vaglienti, A. P. Perrone, A. L. Carenbauer, D. S. Darling and A. M. Cabanillas (2016). "Phosphorylation Regulates Functions of ZEB1 Transcription Factor." Journal of cellular physiology.

Lu, M., M. K. Jolly, H. Levine, J. N. Onuchic and E. Ben-Jacob (2013). "MicroRNAbased regulation of epithelial-hybrid-mesenchymal fate determination." Proceedings of the National Academy of Sciences 110(45): 18144-18149.

Luo, W., W. Fang, S. Li and K. Yao (2012). "Aberrant expression of nuclear vimentin and related epithelial-mesenchymal transition markers in nasopharyngeal carcinoma." International Journal of Cancer 131(8): 1863-1873. 
McKinsey, Gabriel L., S. Lindtner, B. Trzcinski, A. Visel, Len A. Pennacchio, D. Huylebroeck, Y. Higashi and John L. R. Rubenstein "<em>Dlx1\&amp;2</em>Dependent Expression of $<\mathrm{em}>$ Zfhx $1 \mathrm{~b}(\mathrm{Sip} 1</ \mathrm{em}>,<\mathrm{em}>$ Zeb2 $)</$ em $>$ Regulates the Fate Switch between Cortical and Striatal Interneurons." Neuron 77(1): 83-98. Meidhof, S., S. Brabletz, W. Lehmann, B. T. Preca, K. Mock, M. Ruh, J. Schüler, M. Berthold, A. Weber and U. Burk (2015). "ZEB1- associated drug resistance in cancer cells is reversed by the class I HDAC inhibitor mocetinostat." EMBO molecular medicine: e201404396.

Miyoshi, T., M. Maruhashi, T. Van De Putte, H. Kondoh, D. Huylebroeck and Y. Higashi (2006). "Complementary expression pattern of Zfhx1 genes Sip1 and deltaEF1 in the mouse embryo and their genetic interaction revealed by compound mutants." Dev Dyn 235(7): 1941-1952.

Nam, E.-H., Y. Lee, Y.-K. Park, J. W. Lee and S. Kim (2012). "ZEB2 upregulates integrin $\alpha 5$ expression through cooperation with $\mathrm{Sp} 1$ to induce invasion during epithelialmesenchymal transition of human cancer cells." Carcinogenesis.

Nishimura, G., I. Manabe, K. Tsushima, K. Fujiu, Y. Oishi, Y. Imai, K. Maemura, M. Miyagishi, Y. Higashi and H. Kondoh (2006). " $\delta E F 1$ mediates TGF- $\beta$ signaling in vascular smooth muscle cell differentiation." Developmental cell 11(1): 93-104.

Oztas, E., M. E. Avci, A. Ozcan, A. E. Sayan, E. Tulchinsky and T. Yagci (2010). "Novel monoclonal antibodies detect Smad-interacting protein 1 (SIP1) in the cytoplasm of human cells from multiple tumor tissue arrays." Experimental and Molecular Pathology 89(2): 182-189. 
Peinado, H., D. Olmeda and A. Cano (2007). "Snail, Zeb and bHLH factors in tumour progression: an alliance against the epithelial phenotype?" Nat Rev Cancer 7(6): 415-428. Polytarchou, C., D. Iliopoulos and K. Struhl (2012). "An integrated transcriptional regulatory circuit that reinforces the breast cancer stem cell state." Proceedings of the National Academy of Sciences 109(36): 14470-14475.

Postigo, A. A. (2003). "Opposing functions of ZEB proteins in the regulation of the TGFß/BMP signaling pathway." The EMBO journal 22(10): 2443-2452.

Qi, S., Y. Song, Y. Peng, H. Wang, H. Long, X. Yu, Z. Li, L. Fang, A. Wu, W. Luo, Y. Zhen, Y. Zhou, Y. Chen, C. Mai, Z. Liu and W. Fang (2012). "ZEB2 Mediates Multiple Pathways Regulating Cell Proliferation, Migration, Invasion, and Apoptosis in Glioma." PLoS ONE 7(6): e38842.

Rosivatz, E., I. Becker, K. Specht, E. Fricke, B. Luber, R. Busch, H. Höfler and K.-F. Becker (2002). "Differential expression of the epithelial-mesenchymal transition regulators snail, SIP1, and twist in gastric cancer." The American journal of pathology 161(5): 1881-1891.

Sánchez-Tilló, E., Y. Liu, O. de Barrios, L. Siles, L. Fanlo, M. Cuatrecasas, D. Darling, D. Dean, A. Castells and A. Postigo (2012). "EMT-activating transcription factors in cancer: beyond EMT and tumor invasiveness." Cellular and Molecular Life Sciences 69(20): 3429-3456.

Sanchez-Tillo, E., L. Siles, O. de Barrios, M. Cuatrecasas, E. C. Vaquero, A. Castells and A. Postigo (2011). "Expanding roles of ZEB factors in tumorigenesis and tumor progression." Am J Cancer Res 1(7): 897-912. 
Satelli, A. and S. Li (2011). "Vimentin in cancer and its potential as a molecular target for cancer therapy." Cellular and Molecular Life Sciences 68(18): 3033-3046.

Sayan, A. E., T. R. Griffiths, R. Pal, G. J. Browne, A. Ruddick, T. Yagci, R. Edwards, N. J. Mayer, H. Qazi, S. Goyal, S. Fernandez, K. Straatman, G. D. D. Jones, K. J. Bowman, A. Colquhoun, J. K. Mellon, M. Kriajevska and E. Tulchinsky (2009). "SIP1 protein protects cells from DNA damage-induced apoptosis and has independent prognostic value in bladder cancer." Proceedings of the National Academy of Sciences 106(35): 14884-14889.

Schober, M. and E. Fuchs (2011). "Tumor-initiating stem cells of squamous cell carcinomas and their control by TGF- $\beta$ and integrin/focal adhesion kinase (FAK) signaling." Proceedings of the National Academy of Sciences 108(26): 10544-10549. Shiah, S. G., Y. S. Shieh and J. Y. Chang (2016). "The Role of Wnt Signaling in Squamous Cell Carcinoma." J Dent Res 95(2): 129-134.

Siebzehnrubl, F. A., D. J. Silver, B. Tugertimur, L. P. Deleyrolle, D. Siebzehnrubl, M. R. Sarkisian, K. G. Devers, A. T. Yachnis, M. D. Kupper and D. Neal (2013). "The ZEB1 pathway links glioblastoma initiation, invasion and chemoresistance." EMBO molecular medicine 5(8): 1196-1212.

Sun, Z., Z. Zhang, Z. Liu, B. Qiu, K. Liu and G. Dong (2014). "MicroRNA-335 inhibits invasion and metastasis of colorectal cancer by targeting ZEB2." Med Oncol 31(6): 982. Takagi, T., H. Moribe, H. Kondoh and Y. Higashi (1998). "DeltaEF1, a zinc finger and homeodomain transcription factor, is required for skeleton patterning in multiple lineages." Development 125(1): 21-31. 
Tatari, M. N., B. De Craene, B. Soen, J. Taminau, P. Vermassen, S. Goossens, K. Haigh, S. Cazzola, J. Lambert, D. Huylebroeck, J. J. Haigh and G. Berx (2014). "ZEB2transgene expression in the epidermis compromises the integrity of the epidermal barrier through the repression of different tight junction proteins." Cell Mol Life Sci 71(18): 3599-3609.

Techasen, A., W. Loilome, N. Namwat, N. Khuntikeo, A. Puapairoj, P. Jearanaikoon, H. Saya and P. Yongvanit (2014). "Loss of E-cadherin promotes migration and invasion of cholangiocarcinoma cells and serves as a potential marker of metastasis." Tumor Biology 35(9): $8645-8652$.

Tsantoulis, P., N. Kastrinakis, A. Tourvas, G. Laskaris and V. Gorgoulis (2007).

"Advances in the biology of oral cancer." Oral oncology 43(6): 523-534.

Van de Putte, T., A. Francis, L. Nelles, L. A. van Grunsven and D. Huylebroeck (2007).

"Neural crest-specific removal of Zfhx $1 \mathrm{~b}$ in mouse leads to a wide range of neurocristopathies reminiscent of Mowat-Wilson syndrome." Human molecular genetics 16(12): 1423-1436.

Vandewalle, C., F. Van Roy and G. Berx (2009). "The role of the ZEB family of transcription factors in development and disease." Cell Mol Life Sci 66(5): 773-787.

Vered, M., D. Dayan, R. Yahalom, A. Dobriyan, I. Barshack, I. O. Bello, S. Kantola and T. Salo (2010). "Cancer-associated fibroblasts and epithelial-mesenchymal transition in metastatic oral tongue squamous cell carcinoma." Int J Cancer 127(6): 1356-1362. Vigneswaran, N. and M. D. Williams (2014). "Epidemiologic Trends in Head and Neck Cancer and Aids in Diagnosis." Oral and Maxillofacial Surgery Clinics of North America 26(2): 123-141. 
Warnakulasuriya, S. (2009). "Global epidemiology of oral and oropharyngeal cancer." Oral Oncol 45(4-5): 309-316.

Warnakulasuriya, S., J. Reibel, J. Bouquot and E. Dabelsteen (2008). "Oral epithelial dysplasia classification systems: predictive value, utility, weaknesses and scope for improvement." J Oral Pathol Med 37(3): 127-133.

Wellner, U., J. Schubert, U. C. Burk, O. Schmalhofer, F. Zhu, A. Sonntag, B. Waldvogel, C. Vannier, D. Darling, A. zur Hausen, V. G. Brunton, J. Morton, O. Sansom, J. Schuler, M. P. Stemmler, C. Herzberger, U. Hopt, T. Keck, S. Brabletz and T. Brabletz (2009). "The EMT-activator ZEB1 promotes tumorigenicity by repressing stemness-inhibiting microRNAs." Nat Cell Biol 11(12): 1487-1495. Williams, K. r. C., N. E. Renthal, R. D. Gerard and C. R. Mendelson (2012). "The microRNA (miR)-199a/214 Cluster Mediates Opposing Effects of Progesterone and Estrogen on Uterine Contractility during Pregnancy and Labor." Molecular Endocrinology 26(11): 1857-1867.

Woolgar, J. A. (2006). "Histopathological prognosticators in oral and oropharyngeal squamous cell carcinoma." Oral Oncology 42(3): 229-239.

Woolgar, J. A. and A. Triantafyllou (2011). "Squamous cell carcinoma and precursor lesions: clinical pathology." Periodontology 2000 57(1): 51-72.

Yang, Z., B. Sun, Y. Li, X. Zhao, X. Zhao, Q. Gu, J. An, X. Dong, F. Liu and Y. Wang (2015). "ZEB2 promotes vasculogenic mimicry by TGF- $\beta 1$ induced epithelial-tomesenchymal transition in hepatocellular carcinoma." Experimental and Molecular Pathology 98(3): 352-359. 
Zhang, J., X. J. Tian, H. Zhang, Y. Teng, R. Li, F. Bai, S. Elankumaran and J. Xing (2014). "TGF-beta-induced epithelial-to-mesenchymal transition proceeds through stepwise activation of multiple feedback loops." Sci Signal 7(345): ra91.

Zhang, P., Y. Sun and L. Ma (2015). "ZEB1: at the crossroads of epithelial-mesenchymal transition, metastasis and therapy resistance." Cell Cycle 14(4): 481-487. 


\section{CURRICULUM VITA}

NAME: Saira Ahmed

ADDRESS: 2320 Grinstead Drive, Apt. 105

Louisville, KY 40204

DOB: $06 / 15 / 1983$

EDUCATION \& TRAINING:

B.A., History

University of Miami

2001-2006

M.S., Biomedical Science

Florida Atlantic University

2006-2008

AWARDS:

Research!Louisville 2014, $2^{\text {nd }}$ Place Poster Competition

Research!Louisville 2016m $1^{\text {st }}$ Place

ULSD Summer Research Fellowship, 2014

NCI Studentt Training Fellowship, 2016

\section{PUBLICATIONS:}

Sztukowska, M. N., Ojo, A., Ahmed, S., Carenbauer, A. L., Wang, Q., Shumway, B., ... \& Lamont, R. J. (2016). Porphyromonas gingivalis initiates a mesenchymal-like transition through ZEB1 in gingival epithelial cells. Cellular microbiology. 
NATIONAL MEETING PRESENTATIONS:

International Association of Dental Research, 2015, Boston, MA

Subcellular Localization of ZEB2 in Oral Squamous Cell Carcinoma 